STONE CENTER ON SOCIO-ECONOMIC INEQUALITY

WORKING PAPER SERIES

No. 15

Assortative Mating and Labor Income Inequality:

Evidence from fifty years of coupling in the U.S.

Nishant Yonzan

June 2020

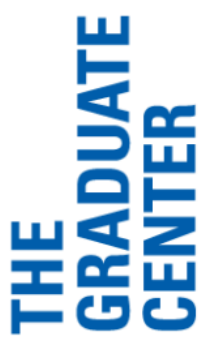

CITY UNIVERSITY

OF NEW YORK 


\title{
Assortative Mating and Labor Income Inequality* Evidence from fifty years of coupling in the U.S.
}

\author{
Nishant Yonzan ${ }^{\dagger}$
}

June 09, 2020

\begin{abstract}
Labor income inequality among couples has increased by 33 percent in the U.S. over the past half-century. Over the same period, the correlation of labor income within couples has also increased sharply. Is this increase in sorting over labor income a cause for the rise of labor income inequality among couples? Using the March supplement of the CPS, first, I find that there has been a sharp increase in positive sorting over labor income in the U.S. in the 1970-2018 period. The top decile of men's earners married to the top decile of women's earners has doubled from 10.6 percent in 1970 to 23.3 percent in 2018. Second, I use a bounded copula framework as a reference distribution to track the relative changes in labor income inequality among couples. Using this framework, I find that positive sorting over labor income did play a role in increasing labor income inequality among couples in the 1970-1990 period; however, I find little evidence to suggest that this relationship existed in the 1990-2018 period.
\end{abstract}

Keywords: Assortative Mating, Labor Income Inequality, Bounded Copula JEL codes: D31, I24, J12

*I would like to thank Miles Corak, Janet Gornick, Inas Rashad Kelly, Branko Milanovic, Salvatore Morelli, and the participants of the Inequality Seminar Series at the Stone Center on Socio-economic Inequality for comments on earlier versions of the paper. The usual disclaimer applies.

†PhD Program in Economics at The Graduate Center, City University of New York; nyonzan@gradcenter. cuny.edu. 


\section{Introduction}

Labor income inequality among couples in the U.S. has increased by 33 percent over the past half-century. Changes in the structure of families have been argued as an important cause of this rise in inequality (see Western, Bloome, and Percheski 2008; McCall and Percheski 2010). In particular, the coupling of like individuals has been an especially popular explanation (see Pencavel 1998; Schwartz and Mare 2005). While some have argued that positive sorting within couples has played a role in increasing income inequality among couples (see Greenwood et al. 2014; Fiorio and Verzillo 2018), others have argued the contrary that sorting plays no role, or even decreases inequality among couples (see Larrimore 2014; Gonalons-Pons and Schwartz 2017; Eika, Mogstad, and Zafar 2019). This paper, first, attempts to observe the trends in labor income correlation within couples - that is, to see who marries whom, and which part of the gender distributions they occupy; and second, to understand if these changes in sorting played any role in the dispersion of labor income among couples in the U.S. over the past fifty years.

Starting with Becker (1973), numerous studies in the economic literature has tried to understand sorting behavior in the marriage market. From production maximizing viewpoint emphasized by Becker - where household utility is maximized with each partner specializing either on the labor market or on the household production tasks, explanations have lately gravitated towards consumption maximizing models - where both partners try to maximize the household consumption of goods and services by increasing their time spent on the labor market (Oppenheimer 1994; Goldin 2006; Stevenson and Wolfers 2007; Gonalons-Pons and Schwartz 2017). Empirical studies have often focused on sorting over some dimensions. Although social and familial connections play a major role in the marriage market, it is difficult to quantify these variables. Hence, an easier to measure variable such as education has been widely used as the medium of sorting within couples. ${ }^{1}$ Even over education, evidence of positive sorting has been inconclusive. Greenwood et al. (2014) find that there has been an increasing trend among individuals positively sorting over their education level - that is, people with a certain level of schooling tend to marry others with a similar level of schooling (also see Schwartz and Mare 2005; Jepsen 2005). On the other hand, Gihleb and Lang (2016) find little evidence of substantial change in homogamy based on education. They argue that positive sorting over education is highly dependent on the choice of statistical techniques used. Concerns also arise if education has a differential effect on sorting. Eika, Mogstad, and

\footnotetext{
${ }^{1}$ Choice of education could be an indicator not only of the labor market but also of the marriage market. Chiappori, Salanié, and Weiss (2017) attribute the higher education among women relative to men to positive marital-returns-to-schooling for women.
} 
Zafar (2019) find that while there is positive sorting within low-educated couples, this is not the case for high-educated couples.

This paper does not attempt to explain the factors driving the matching decision of couples. Behavioral decisions underlying marital sorting, be it through education, or along any other dimension, could well be endogenous to income. Sorting over income could be both a function of individuals with similar levels of income before marriage pairing with each other, or, it could be a behavioral response to the partner's level of income after, or in expectation of, marriage (for a sample of studies explaining sorting mechanisms see Becker 1973; Choo and Siow 2006; Dupuy and Galichon 2014).

This study focuses on the correlation of labor income within couples. First, I study the incomeincome correlation between the two marginal gender distributions and an income-income correlation between the marginal and joint distributions. Using the income associations, I find that in 2018 top percentile of women's earners contributed 55 percent of their income to the top percentile of couple's earners ranked in their respective distributions. The same contribution of the top-earning women in 1970 was only 24 percent. On the other hand, the top percentile of men's contribution only slightly decreased from 87 percent in 1970 to 82 percent in 2018. This is consistent with the finding in Yavorsky et al. (2019). Using the Survey of Consumer Finance, they find that, despite the positive changes in earnings of the top-earning women, top-earning couples' incomes are still highly dependent on top-earning men's incomes. In addition to the income-income correlations, I also find positive sorting using a rank-rank correlation between the two marginal labor income distributions. Whereas 12.4 percent of men from the men's top-earning decile were married to women from the women's bottom earning decile in 1970, the share of top decile men marrying the bottom decile women has decreased to 10.5 percent in 2018. On the other hand, the top-earning decile of men marrying the top-earning decile of women has doubled from 10.6 percent in 1970 to 23.3 percent in 2018.

Changes in labor market behavior have added complications to studying the effect of positive sorting on income inequality. An increasing share of women has joined the formal labor force in the past fifty years. There has been a 100 percent increase in the number of women with positive labor earnings in the U.S. from 1970 to $2018 .^{2}$ The increase in labor market participation among women has changed the economic dimension both within and across families. Using the Current Population Survey (CPS) data for the years 1979 and 1989, Cancian and Reed (1998) compare couples' distribution with a reference distribution where the wife has zero earnings. Compared to the reference distribution, they find that having

\footnotetext{
${ }^{2}$ See Table 2.
} 
an additional earner in the family reduces earnings inequality across families. In a similar vein, OECD (2011) find increased women's labor force participation, on average, decreased overall earnings inequality across households in 24 countries. ${ }^{3}$ Furthermore, marital behavior has also changed over the past half-century. While 23 percent of $20-65$ population in the U.S. were single in 1970, the share of singles has increased to 44 percent in $2018 .{ }^{4}$ This increase in the number of single-earning households could also affect income inequality across households of various sizes. Indeed, Dupuy and Weber (2019) find that those choosing to remain single accounts for 95 percent of the rise in inequality across households, while education sorting contributes to only the remaining 5 percent. This paper focuses only on the married population. Focusing on this sub-sample accounts for the effect of the changes in the size of households on labor income inequality across them. ${ }^{5}$

Demographic and labor market changes, conflated with the positive sorting within couples, affect labor income inequality. They could all act to change inequality in the same direction; alternately, these changes could act in the opposite direction (see OECD 2011; Gonalons-Pons and Schwartz 2017). Hence, it is difficult to tease out the role of assortative mating on the rise in labor income inequality among couples. To that end, researchers have employed counterfactual distributions to help isolate the role of sorting while keeping other variables fixed. In one such study, Reed and Cancian (2012) use the CPS data from 1968-2003 to compare the current level of income inequality to a counterfactual distribution with sorting levels fixed at the level in the 1960s. They find that positive income sorting accounts for almost half of the increases in family income inequality in that time frame. Similarly, Greenwood et al. (2014) employ two counterfactuals - first, a randomly matched couples' distribution and second, a randomly matched couples' distribution conditional on some level of education sorting. ${ }^{6}$ Using both counterfactuals, they find that income inequality among couples has slightly increased compared to a random distribution due to the positive sorting of individuals based on their level of education.

Results based on counterfactual studies, however, are often dependent on the choice of counterfactual. Randomly matched distributions are informative, but purely random matching

\footnotetext{
${ }^{3}$ For studies focused on the welfare effects of changing shares of incomes with families, among others, see Bloome, Burk, and McCall (2019), Yavorsky et al. (2019).

${ }^{4}$ See Table 1. This change was most drastic in the younger cohorts. For the 20-35 age group, the proportion of singles increased from 30 percent in 1970 to 62 percent in 2018.

${ }^{5}$ In addition, this paper tracks the trends in age-specific groups where applicable. The age cohorts are created by dividing the 20-65 population into the following groups: 20-35, 36-50, and 51-65. The trends in these age groups are compared and contrasted with that of the overall married population (age group 20-65).

${ }^{6}$ They define educational sorting as the probability that individuals positively match according to their educational outcomes, which they keep fixed at the 1960 level.
} 
within couples is rare. ${ }^{7}$ If not over income, other variables, both measurable and unmeasurable, form the basis over which individuals tend to sort. To take an extreme case, assume that marriages are decided by families, or that it is outside the control of the concerned individuals. Sorting here could happen over familial variables such as income, wealth, religion, political or social standing of families, or the labor market prospect of the concerned individuals. In this case, matching occurs over some societal outcome, and this outcome is very frequently is associated with income and/or wealth of the family. At the other extreme, consider a partnership that is solely dependent on the concerned individuals, that is through their choice alone. In this union, one generally tends to choose a partner with whom they share some common interests or goals. At a minimum, they need to meet somewhere. This meeting could happen at the place of education, work, entertainment, or the like. However, interests such as education, work, choice of sports, and music which provide these meeting spaces are generally correlated with one's, or that of their family's, level of income or wealth. Thus, any sorting is likely to happen over some measure of income or wealth. Chance meetings are possible but are dependent on the probability of being in a particular venue which is in turn related to one's income. For instance, consider education as the sorting (meeting) variable. Recent intergenerational research has highlighted the importance of family wealth to college placement (Chetty et al. 2014) and through it the coupling of individuals.

To capture the changes in inequality due to labor-income sorting, this paper employs the Frechet-Hoeffding bounded copula as proposed in Nelsen (1999) and Nelsen (2007). ${ }^{8}$ This framework creates an upper and a lower bound for inequality among couples holding fixed the current labor market behavior of married individuals. All else equal, the bounds are dependent on the coupling of the marginal distributions. What is important here is that inequality of any other reference distribution, random or otherwise, will fall within these bounds. While much of the literature have compared the changes in inequality of the current joint distribution to the inequality of a particular distribution - such as a random distribution, this paper compares the changes in inequality of the joint distribution as a function of the distance from the bounds - that is, it will show how far away from the lowest level of inequality or how much closer to the highest level of inequality the current joint distribution has moved. We can thus track the changes in inequality with respect to the changes in the position of the current joint distribution of couples to the extremes.

\footnotetext{
${ }^{7}$ For a sample of studies that have used randomly matched distribution to study assortative mating see Hryshko, Juhn, and McCue (2017), Pestel (2016), Fiorio and Verzillo (2018), and Eika, Mogstad, and Zafar (2019).

${ }^{8}$ For a sample of studies that have applied a bivariate copula-based method to study welfare see Dardanoni and Lambert (2001), Quinn (2009), Bø, Lambert, and Thoresen (2012), Atkinson and Lakner (2017), and Aaberge, Atkinson, and Königs (2018).
} 
Using the bounded framework, I find that assortative mating did play a role in increasing labor income inequality among couples in the 1970-1990 period. This is consistent with the findings in Reed and Cancian (2012). However, consistent with the findings in Larrimore (2014), there is little evidence to suggest that positive sorting over labor income played a role in the increase in labor income inequality among couples in the 1990-2018 period. In the latter period, Larrimore (2014) attributes the increase in household income inequality to the increase in the female earnings inequality, while Gonalons-Pons and Schwartz (2017) have argued that changes in shifts in the division of paid labor within couples were most important for the increased inequality among them.

The remainder of this paper proceeds as follows. Section 2 describes the data, descriptive statistics, and methodology. Section 3 presents the findings in assortative mating and its effect on labor income inequality. The final section offers some concluding remarks.

\section{Data, Descriptive Statistics, and Methodology}

\subsection{Data and Variables}

For this study, I rely on the Current Population Survey data available from the Integrated Public Use Micro Sample files (IPUMS-CPS). ${ }^{9}$ In particular, I use the March Annual Social and Economic Supplement (ASEC) samples for the years 1970, 1980, 1990, 2000, 2010 and 2018.

I make three restrictions on the data. First, since the focus of this paper is the correlation of labor earnings between heterosexual couples and its subsequent effect on the inequality of income from labor, I construct an earnings variable - labor income. Labor income is defined as pre-tax earnings generated from either working for an employer or from one's self-employment. ${ }^{10}$ To construct this variable of interest, I combine three IPUMS-CPS income items - incwage (personal pre-tax income from wages and salary), incbus (net pre-tax non-farm income from personal business and/or professional practices), and incfarm (personal net pre-tax income as a farmer, sharecropper, or operator of his/her farm).

Second, the data includes only the married population. People who are reported single, divorced, or widowed are not part of this study. This study focuses on the labor market

\footnotetext{
${ }^{9}$ Sarah Flood and Warren (2017), https://cps.ipums.org/cps/.

${ }^{10}$ Previous studies have used wage income as the earnings variable. Keeping income only from wages leaves out the self-employed. Since the focus of this study is the correlation of earnings of couples, I include both wage earners and the self-employed.
} 
behavior of those individuals conditioned on the fact that they are married or can be identified in the data as a couple. There have been changes in the share of these groups in the population over the past half-century. Stevenson and Wolfers (2007) suggest that this fall in the share of married individuals is primarily driven by younger cohorts marrying later than their parents. However, they also find that the share of divorces, which peaked in 1980, has been declining. So, despite more people marrying later, once married, they seem to be staying married longer. It is beyond the scope of this paper to explain these trends. I do control for these secular trends by looking at specific age-groups where applicable.

The third restriction is the age of individuals. Since the principals of this study are workingage population, my sample focuses on the individuals in the labor force; more precisely, individuals who are between 20 and 65 -year-old at the time of the survey. ${ }^{11}$ Besides, where applicable, I present results controlling for specific age groups: that is the trends in 20-35, 36-50, and 51-65 age groups.

All reported labor income in this study is reported in 2015 U.S. dollars. All income inequality discussed here is calculated for the labor income concept define above. Furthermore, the Census Bureau started using rank proximity swapping procedure starting 2011. For comparability to the data before 2011 they also provide cell mean replacement values, which I have used for this study. ${ }^{12}$

Further, I report the trends for three distributions: a joint distribution - labor income distribution of couples, and two marginal distributions based on one's gender - labor income distribution of married men, and labor income distribution of married women. The joint distribution includes all individuals that can be matched in the IPUMS-CPS. I define a couple as married heterosexual individuals and heterosexual individuals who are identified as a couple and are living together in the same household. ${ }^{13}$

\footnotetext{
${ }^{11}$ Greenwood et al. (2014) restrict the age group to 25-54. Since their study focuses on education as a sorting variable, they restrict their sample to those over 25. Since the interest in this study is mating patterns, I include the over 20 population. As the current paper also looks at the effect of labor earnings, I do not include those over the retirement age in the U.S. (that is over the age of 65).

${ }^{12}$ These "swap" values are income component cell means replacement values which "preserves the distribution of values above the [income variable] threshold, but preserves privacy, as the income value in the data will not be the one that that respondent reported." They are used in-lieu of censuring incomes of the top-earners. Since they replace the average income within certain demographics groups, the swap-adjusted data closely match the shares of the top income earners in the public use CPS file to the restricted (and more accurate) internal files; see Larrimore et al. (2008) for detail. Swap values are available from the IPUMS-CPS for the years 1976-2010: https://cps.ipums.org/cps/income/_cell/_means.shtml.

${ }^{13}$ I use the sploc variable in the CPS to identify couples. Sploc indicates whether a person's partner lives in the same household and if so, identifies the partner. I have referred to identifiable partners as married. Same-sex couples can only be identified in the IPUMS-CPS starting in 2016, so this study focuses on heterosexual couples. All mentions of men and women in this paper refer to married men and married women unless otherwise noted.
} 


\subsection{Descriptive Statistics}

Table 1 reports the total number of units by year in each of the three distributions. It also reports the share of married individuals for the marginal distributions. There are a total of 191,599 men and 199,443 women in the full sample - the 20-65 age group. ${ }^{14}$ There are 28,790 married men in 1970 and 27,967 in 2018. This represents 79 percent of all men in the survey in 1970 and 57 percent in 2018. Similarly, the corresponding number in the full sample for women is 74 percent married in 1970 and 55 percent in 2018. Looking at specific age groups, there are more men married in the older age groups than in the younger age group. Sixty-seven percent of the men in the 20-35 age group are married in 1970, while 87 percent and 86 percent are married in the 36-50 and 51-65 groups respectively in that same year. By 2018, the share of married men in the various age groups decreases to 34 percent, 69 percent, and 68 percent respectively. For the women, the corresponding number is 71 percent of 20-35 group, 81 percent of 36-50 group, and 69 percent of 51-65 group in 1970, and 40 percent, 66 percent, and 61 percent respectively in 2018.

The joint distribution has a total of 192,203 couples overall. Of the 27,810 couples in 1970, 8,953 (32 percent) are in the 20-35 age group, 10,454 (38 percent) are in the 36-50 age group, and 8,403 (30 percent) are in the 51-65 age group. In 2019, of the 29,100 couples, 6,440 (22 percent) are in the 20-35 age group, 12,226 (42 percent) are in the 36-50 age group, and 10,434 (36) are in the 51-65 age group.

\footnotetext{
${ }^{14}$ Two percent of men and women who are identified as with partners could not be matched to a heterosexual partner in the data. I keep them in their respective gender distributions but the unmatched individuals are excluded from the joint distribution. Using these individuals does not change the outcome of the study.
} 
Table 1: Descriptive Statistics, Units

\begin{tabular}{|c|c|c|c|c|c|c|c|c|}
\hline & & & \multicolumn{6}{|c|}{ Age Group } \\
\hline & \multicolumn{2}{|c|}{ Full Sample } & \multicolumn{2}{|c|}{$20-35$} & \multicolumn{2}{|c|}{$36-50$} & \multicolumn{2}{|c|}{$51-65$} \\
\hline & Units & Share $(\%)$ & Units & Share $(\%)$ & Units & Share $(\%)$ & Units & Share $(\%)$ \\
\hline & \multicolumn{8}{|c|}{ Panel A: Joint Distribution } \\
\hline 1970 & 29,263 & - & 8,953 & - & 10,454 & - & 8,403 & - \\
\hline 1980 & 35,232 & - & 12,080 & - & 11,513 & - & 9,893 & - \\
\hline 1990 & 29,229 & - & 8,272 & - & 11,841 & - & 7,610 & - \\
\hline 2000 & 41,329 & - & 9,723 & - & 19,044 & - & 10,274 & - \\
\hline 2010 & 37,891 & - & 7,858 & - & 15,179 & - & 12,006 & - \\
\hline \multirow[t]{2}{*}{2018} & 32,174 & - & 6,440 & - & 12,226 & - & 10,434 & - \\
\hline & \multicolumn{8}{|c|}{ Panel B: Men's Distribution } \\
\hline 1970 & 28,790 & 79.17 & 9,726 & 67.54 & 10,627 & 87.50 & 8,437 & 85.92 \\
\hline 1980 & 34,601 & 69.51 & 12,976 & 54.69 & 11,546 & 82.24 & 10,079 & 83.92 \\
\hline 1990 & 28,588 & 64.11 & 9,057 & 47.00 & 11,740 & 74.84 & 7,791 & 80.84 \\
\hline 2000 & 38,011 & 63.94 & 9,615 & 45.26 & 18,461 & 73.17 & 9,935 & 76.58 \\
\hline 2010 & 33,642 & 58.73 & 7,190 & 36.69 & 14,811 & 69.98 & 11,641 & 70.48 \\
\hline \multirow[t]{2}{*}{2018} & 27,967 & 56.62 & 5,737 & 33.78 & 11,891 & 68.91 & 10,339 & 68.22 \\
\hline & \multicolumn{8}{|c|}{ Panel C: Women's Distribution } \\
\hline 1970 & 29,695 & 73.60 & 11,495 & 70.80 & 10,667 & 80.96 & 7,533 & 68.87 \\
\hline 1980 & 35,811 & 66.53 & 15,107 & 60.08 & 11,389 & 75.33 & 9,315 & 68.67 \\
\hline 1990 & 29,846 & 61.88 & 10,979 & 52.91 & 11,610 & 69.56 & 7,257 & 67.25 \\
\hline 2000 & 39,437 & 61.30 & 11,908 & 50.72 & 18,714 & 69.36 & 8,815 & 63.55 \\
\hline 2010 & 35,081 & 56.63 & 9,167 & 42.27 & 15,075 & 66.12 & 10,839 & 62.07 \\
\hline 2018 & 29,573 & 55.44 & 7,254 & 39.87 & 12,246 & 65.54 & 10,073 & 61.19 \\
\hline
\end{tabular}

Notes: This table reports the total number of couples and married individuals in each distribution, and, for the men's and women's distribution, the share (in \%) of individuals in survey sample who are married in that year. Each observation in the joint distribution is a couple. Full Sample includes married individuals in the 20-65 age group. Source: IPUMS-CPS (https://cps.ipums.org/cps/).

Couples' incomes have risen over the past fifty years. Table 2 reports the mean and median income of the three distributions. Average couples income rose from $\$ 66,190$ in 1970 to $\$ 98,052$ in 2018 . This 1.5 fold increase in the mean income of couples was mostly driven by the increase at the top of the income distribution. Their median income rose by 1.2 folds, from $\$ 62,048$ in 1970 to $\$ 75,511$ in $2018 .{ }^{15}$ While the mean and median levels of income vary for the different age groups, the trends in changes over the past fifty years is fairly similar as

\footnotetext{
${ }^{15}$ Figure A.1 shows the changes in the dispersion of labor income for the marginal distributions in 1970 and 2018.
} 
the overall population.

Men's average income rose 16 percent between 1970 and 2018. What is interesting to note is that the median earnings of men decreased by 5 percent in the same time frame. This decrease in median income is largest for the youngest age group, declining 12 percent over the past half-century. The median income of the 36-50 group was fairly stable, and the median income of the 51-65 group declined by 3 percent in the same time frame. Mean income, on the other hand, rose sharpest for the older cohort - rising by 21 percent, then for the 36-50 population - rising by 14 percent, and finally for the 20-35 group - rising by 7 percent. Among men, there has been an increase in those with zero labor income - from 5.5 percent to 12.0 percent for the full sample. Five percent of the men in the 20-50 age bracket and nineteen percent in the 51-65 group had no labor income in 2018.

The number of women who have joined the formal labor force has sharply increased over the past fifty years. Table 2 shows that while 49 percent of women did not have positive income in the labor market in 1970, only 28 percent did not do so in 2018. This increase in the labor force participation among married women is consistent in all age groups, with the "oldest" cohort with the highest share - 34 percent - without labor income. This secular change in the formal labor force participation among women perhaps accounts for the sharp rise in both the mean income - from $\$ 11,004$ to $\$ 34,084$, and the median income - from $\$ 293$ to $\$ 23,597$ - for women in the 1970-2018 time period.

\subsection{Methodology}

\subsubsection{Assortative Mating}

To describe the changes in observed mating patterns of couples over labor income, I employ two approaches. First, I use an income-based approach that measures the association between the marginal and the joint distribution relative to the amount of income in each distribution. Since this measure is sensitive to the changes in the levels of income, second, I use a rankbased approach that captures the positional correlation between the marginal and joint distributions.

\subsubsection{Income based association}

Let's first define the share of income of the $i^{\text {th }}$ income-group of the joint distribution as follows: 


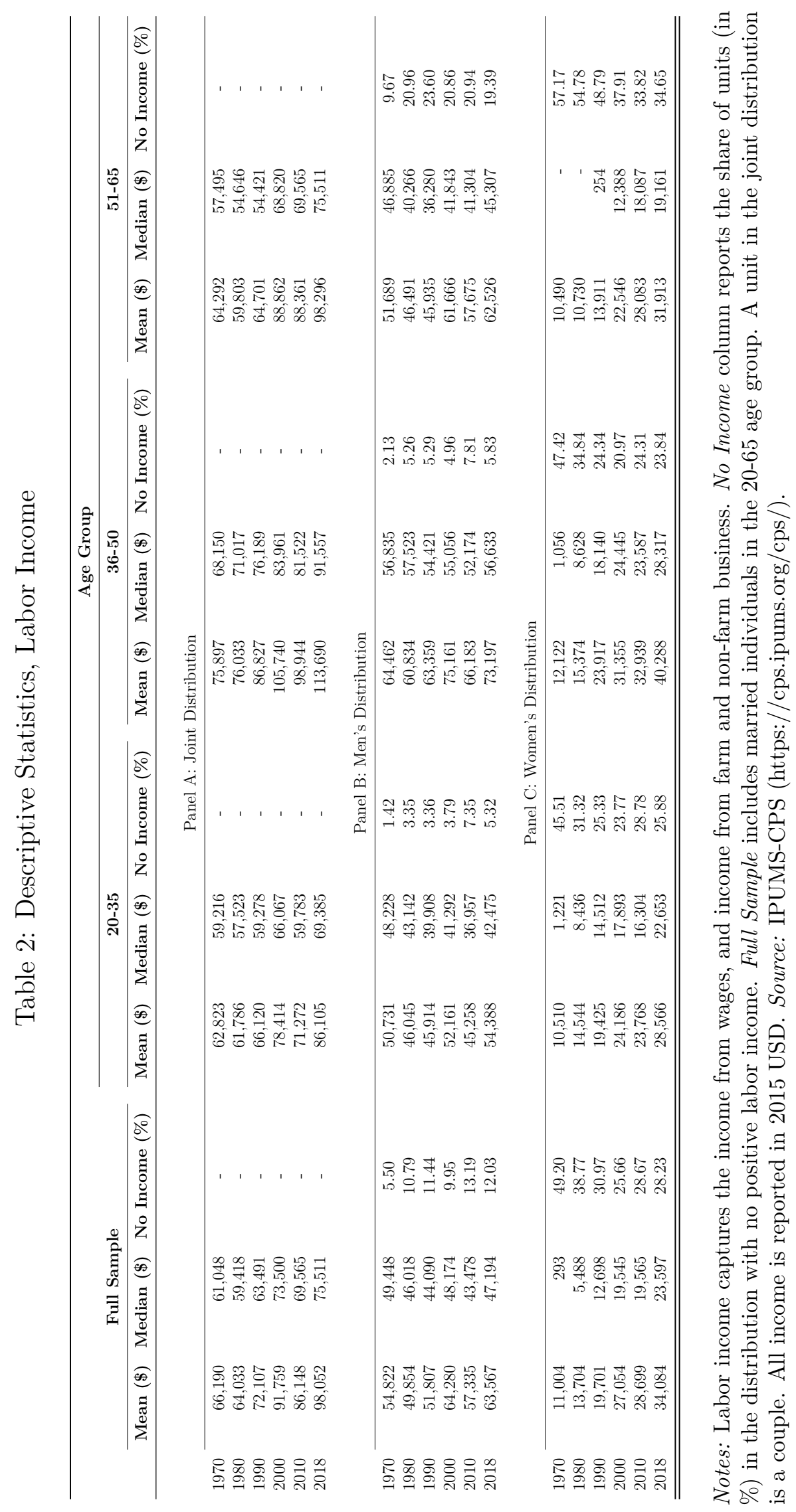




$$
S_{i}=\frac{Y_{i}}{Y}=\frac{\sum_{g=1}^{2} \tilde{X}_{i g}}{Y}
$$

where $Y$ is the total income of the joint income distribution and $Y_{i}$ is the total income of income-group $i$ in the same distribution. For instance, the share of income of the top one percent income-earning couples. A couple is in the group $i$ if their income $y_{j}$ is at least as large as the income threshold $y_{i}$. We can further decompose $Y_{i}$ into income from the respective partners. $\tilde{X}_{i g}$ represents the total income of the individuals in the marginal distributions, which is from gender-group $g$, who belong to the income-group $i$ of the joint distribution. That is

$$
\tilde{X}_{i g}=\sum_{j=1}^{N} x_{j g} \times \mathbb{1}\left\{y_{j} \geq y_{i}\right\}
$$

where $x$ is the total income of an individual of the gender-group $g$.

Note that $\tilde{X}_{i g}$ is different from $X_{i g}$, which is the total income of the individuals in each marginal distribution in the group $i$ of their own marginal distribution. That is

$$
X_{i g}=\sum_{j=1}^{N} x_{j g} \times \mathbb{1}\left\{x_{j} \geq x_{i}\right\}
$$

with $X_{i g} \geq \tilde{X}_{i g}$. While $X_{i g}$ captures the total income of the income-group in the gender distribution, $\tilde{X}_{i g}$ reflects the total income of this group that is also in the corresponding joint distribution. For instance, while the former would be all the income of the top one percent female earners, the latter would be the total income of these earners in the top one percent of couples.

Following Atkinson (2007), we can decompose the income share into the following:

$$
S_{i}=\sum_{g=1}^{2} \underbrace{\frac{X_{g}}{Y}}_{1} \cdot \underbrace{\frac{X_{i g}}{X_{g}}}_{2} \cdot \underbrace{\frac{\tilde{X}_{i g} / X_{g}}{X_{i g} / X_{g}}}_{3}
$$

where (1) measures each gender's contribution in the total income of the joint distribution; (2) measures the within-gender income inequality - in other words, it calculates the share of income held by each income-group $i$ in their own gender distributions; and (3) measures the association of income of $i^{t h}$ income-group of the marginal distribution to that of the joint distribution. Following Atkinson (2007) this is referred to as the alignment coefficient, or $\alpha_{i g}$. 
A higher value of $\alpha_{i g}$ represents a greater income association. In particular, the alignment coefficient shows the percentage income of marginal distribution from the $i^{\text {th }}$ percentile that falls into the same percentile of the joint distribution. For example, an $\alpha_{i g}$ equal to one would imply a perfect association of income between the marginal and joint distributions. That is to say, all income of the individuals in the income-group of the marginal distribution would be found in the same income-group of the joint distribution. We can rewrite the alignment coefficient as follows:

$$
\alpha_{i g}=\frac{\tilde{X}_{i g}}{X_{i g}} \in[0,1]
$$

Note that if $\tilde{X}_{i g}=X_{i g}$ then $\alpha_{i g}=1$.

\subsubsection{Rank based association}

An income-based measure is susceptible to changes in the levels of income. As discussed above, income levels have certainly changed in the past fifty years. To account for the effect of these changes on the income correlation, I look at rank-rank based correlation methods.

First, I look at the rank-rank based association between each marginal distribution and the joint distribution. In particular, this rank-based association measures the probability that an individual from a certain income group in the marginal distribution moves to, or stays in, various income groups in the joint distribution. For this purpose, I divide each of the marginal and joint distributions into five quintiles ranked by their labor income. Then I track the position of an individual in the marginal distribution and their position in the joint distribution. The probabilities calculate the share of individuals in the joint distribution who remain in the same quintile as their marginal distribution, and the share that moves to various quintiles of the joint distribution. In essence, this would proxy "mobility" due to marriage.

Second, I will look at the rank-rank association between gender distributions. Instead of looking at the rank-rank association between the marginal and joint distributions, we can also look at the rank-rank association between the two marginal distributions. This method shows the share of individuals in a particular income group in one gender distribution married to the various income groups of the opposite gender distribution. For example, this rank-rank association between the top men's income decile and top women's income decile would equal 100 percent of all the top decile earners in the men's distribution were married to all the top decile earners in the women's distribution; conversely, it would equally be zero percent if all 
the top decile earners in the men's distribution were married to women in the bottom 90 percent of the women's distribution.

\subsubsection{Labor Income Inequality}

Rather than use the random distribution as a baseline, for the reasons cited earlier, I construct a pair of counterfactual joint distributions that create bounds for all possible income inequality arising from the formation of couples. These reference distributions make no further assumption on the behavior of the individuals. The upper bound is a distribution that has perfect sorting over labor income. In this perfect-pair distribution the top-earning men from the men's labor income distribution are paired with top-earning women from the women's labor income distribution. By construction, the perfectly-paired distribution has the highest possible labor income inequality at the current level of individuals' labor income. For the lower bound, I do the exact opposite. The top-earning women are paired with the least earning men and vice versa. This opposite-pair distribution represents the lowest possible inequality due to sorting keeping fixed the current labor market behavior.

In literature, this bounded framework is referred to as the Frechet-Hoeffding bounds (see Nelsen 2007). Frechet-Heoffding bounds can be presented as:

$$
\max \left(F\left(x_{1}\right)+G\left(x_{2}\right)-1,0\right) \leq H\left(x_{1}, x_{2}\right) \leq \min \left(F\left(x_{1}\right), G\left(x_{2}\right)\right)
$$

where $H\left(x_{1}, x_{2}\right)$ is the current joint distribution, and $F\left(x_{1}\right)$ and $G\left(x_{2}\right)$ are the marginal distributions. The lower bound (opposite-pair) is referred to as the countermonotonic copula and the upper bound (perfect-pair) is referred to as the comonotonic copula. Note that inequality of any other joint distribution, random or otherwise, will fall within the FrechetHeoffding bounds. ${ }^{16} \mathrm{I}$ will discuss the inequality trends in the current couples distribution relative to these bounds. An increase in inequality can be defined as a movement towards the comonotonic copula, or a movement away from the countermonotonic copula.

\footnotetext{
${ }^{16}$ An example of the comonotonic and countermonotonic distributions as well as a random distribution is presented in the Appendix Figures A.2 and A.3.
} 


\section{Results}

\subsection{Assortative Mating}

\subsubsection{Alignment Coefficient}

Table 3 reports the $\alpha_{i g}$ for various income groups. Recall that an $\alpha_{i g}=1$ would imply that all the income of income group $i$ of gender group $g$ is accounted for in the same income group $i$ of the joint distribution. While $\alpha_{i g}=1$ would imply a perfect correlation of income between the marginal and joint distribution, $\alpha_{i g}=0$ would imply the opposite - that no income from a group $i$ is present in the same income group of the joint distribution. Income from the men's distribution is highly associated with the income of the joint distribution compared to the income from the women's distribution. $\alpha$ for the Top 1 percent men's income group was 0.87 in 1970, and 0.82 in 2018. This implies that 87 percent of the income of the top-earning percentile in the men's distribution was also found in the top percentile of the joint distribution in 1970, and 82 percent of it was found in 2018. Compared to this, only 24 percent of the income of the top-earning women was accounted for in the top percentile of the joint distribution in 1970; this has increased to 55 percent in $2018 .^{17}$

While men's income was strongly correlated with the income of couples in the past, it still remains so especially at the top of the income distribution. Looking at the bottom half of the income distribution, men's income association was 76 percent in both 1970 and also in 2018 . Women's income association for the same income group increased from 64 percent in 1970 to 72 percent in 2018. In 1970, the men-to-women income ratio for the top percentile was 3 folds larger than the same ratio of the bottom fifty percent of the distribution $(0.87 / 0.24=$ $3.625 ; 0.76 / 0.64=1.188)$. This ratio has decreased to 1.4 folds in favor of the top percentile in $2018(0.82 / 0.55=1.491 ; 0.76 / 0.72=1.056)$. This was due to more women moving into the labor force and the simultaneous increases in their earnings. While there has been a steady increase in the share of income in the joint distribution coming from women, men's income still represents a significantly large share. Figure 1 shows the share of overall income in the joint distribution coming from each gender. Men's income accounted for 83 percent of the couples' income in 1970 and 65 percent in 2018. Women's income, despite the increases over the past half-century, still accounts for only a third of the share of the total income in the joint distribution in 2018.

\footnotetext{
${ }^{17}$ The changes in trends for the various age groups are similar to the full population. See Appendix Tables A.1, A.2, and A.3 for detail.
} 
Table 3: Alignment Coefficent, 20-65 age group

\begin{tabular}{lcccccc}
\hline & $(1)$ & $(2)$ & $(3)$ & $(4)$ & $(5)$ & $(6)$ \\
& 1970 & 1980 & 1990 & 2000 & 2010 & 2018 \\
\hline \multicolumn{7}{c}{ Panel A: Men's Distribution } \\
\cline { 2 - 7 } Top 1\% & 0.87 & 0.84 & 0.85 & 0.79 & 0.83 & 0.82 \\
Top 5\% & 0.81 & 0.80 & 0.79 & 0.86 & 0.81 & 0.79 \\
Top 10\% & 0.79 & 0.77 & 0.78 & 0.84 & 0.79 & 0.80 \\
Top 5-1\% & 0.70 & 0.67 & 0.63 & 0.69 & 0.64 & 0.60 \\
Top 10-1\% & 0.72 & 0.69 & 0.68 & 0.72 & 0.68 & 0.69 \\
Middle 40\% & 0.74 & 0.76 & 0.75 & 0.75 & 0.75 & 0.75 \\
Bottom 50\% & 0.76 & 0.75 & 0.75 & 0.75 & 0.75 & 0.76 \\
\hline \multicolumn{7}{c}{ Panel B: Women's Distribution } \\
Top 1\% & 0.24 & 0.24 & 0.33 & 0.50 & 0.44 & 0.55 \\
Top 5\% & 0.32 & 0.34 & 0.45 & 0.53 & 0.53 & 0.64 \\
Top 10\% & 0.42 & 0.44 & 0.54 & 0.58 & 0.60 & 0.67 \\
Top 5-1\% & 0.16 & 0.17 & 0.26 & 0.23 & 0.29 & 0.38 \\
Top 10-1\% & 0.31 & 0.33 & 0.42 & 0.41 & 0.47 & 0.52 \\
Middle 40\% & 0.56 & 0.56 & 0.61 & 0.62 & 0.63 & 0.66 \\
Bottom 50\% & 0.64 & 0.65 & 0.68 & 0.69 & 0.69 & 0.72 \\
\hline \hline
\end{tabular}

Notes: $\alpha_{i g}$ measures the association of income between each gender distribution, $g$, and the joint distribution for a particular income group, $i$. For detail see Equation 5 . Top 1\%, 5\%, and $10 \%$ report income shares held by those income groups in each income distribution. Top 5-1\% (10-1\%) is the income group that represents income of the top 5 (top 10) percent income earners excluding the income of the very top percentile. Source: Authors' calculation using IPUMS-CPS (https://cps.ipums.org/cps/). 
Figure 1: Share of Income in the Joint Distribution from each Gender

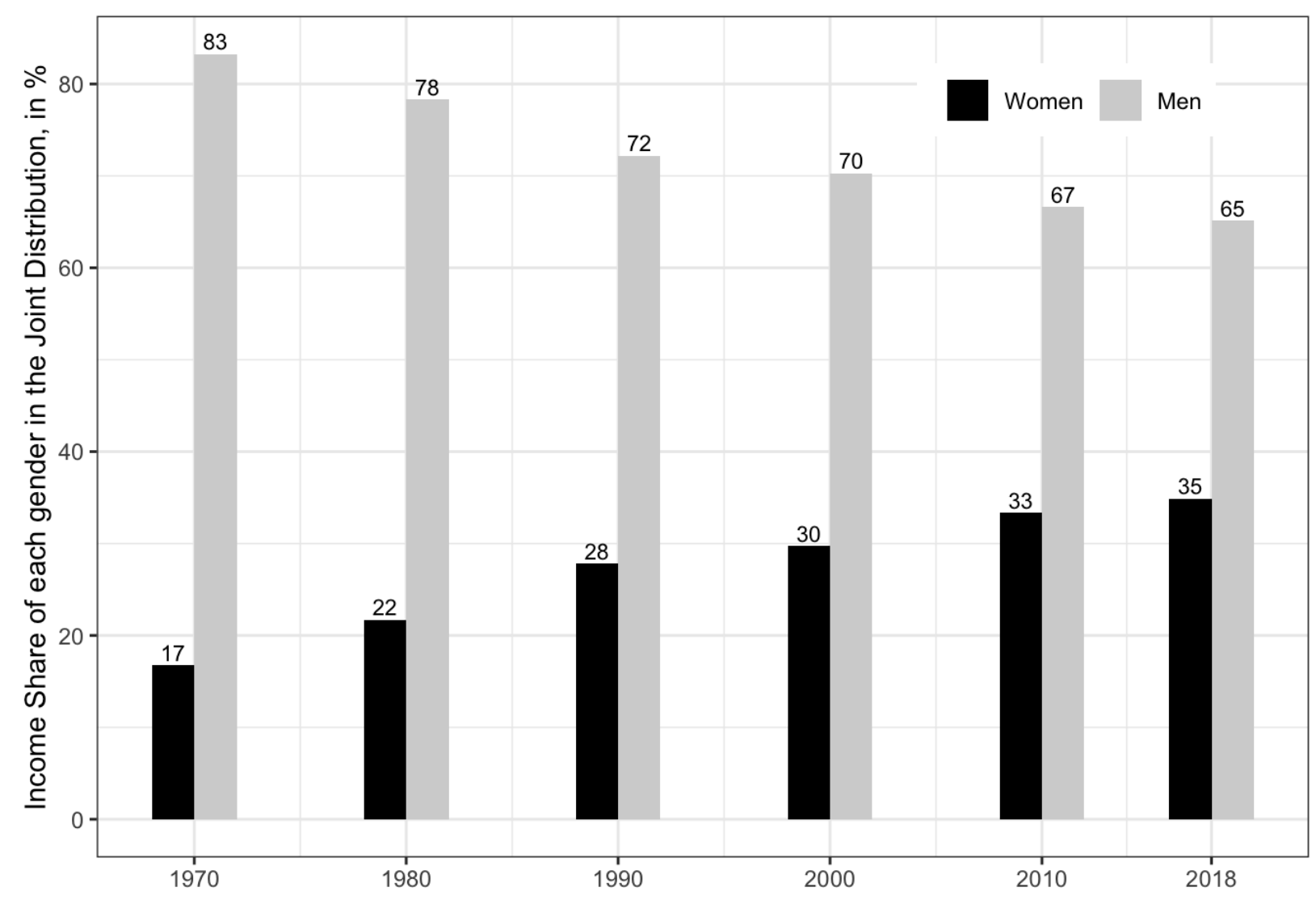

Notes: This figure reports the share of income in the joint distribution from each marginal gender distribution. These values are calculated using part (1) of Equation 4. Source: Authors' calculation using IPUMS-CPS (https://cps.ipums.org/cps/). 


\subsubsection{Rank-rank associations}

Instead of looking at the association of the level of income between the marginal and joint distribution, I next look at the rank-based association between the two distributions. Further, I will also look at the rank-rank association between the two marginal gender distributions.

\subsubsection{Rank-rank association between the marginal and joint distribution}

The top panels in Table 4 show the "mobility-by-marriage" probabilities of men in 1970 (Panel A) and in 2018 (Panel B). Likewise, the women's probabilities are presented in panels $\mathrm{C}$ and D. Each panel is divided into quintiles by labor income ranked from the poorest (1st) to the richest (5th) quintile. Each entry shows the share of individuals from a particular income group in the gender distribution moving to various income quintiles of the joint distribution. The diagonals in each panel show the share of individuals in each gender quintile staying in the same quintile as the couples' distribution. While 26.3 percent of women (Panel C, Row 1, Column 1) from the bottom quintile of the women's distribution remained in the same quintile in the joint distribution in 1970, 43.9 percent stayed in the bottom quintile in 2018 (Panel D, Row 1, Column 1). Another way of saying this is that there has been a 68 percent increase in the probability that a woman in the bottom quintile of the marginal distribution remains in the bottom quintile of the joint distribution after marriage. At the same time, while 15.0 percent of women (Panel C, Row 5, Column 1) moved from the bottom quintile of the women's distribution to the top quintile in the couples' distribution, only 9.9 percent (Panel D, Row 5, Column 1) made the same move in 2018 - a 34 percent decline.

Overall, there has been an increase in the likelihood that women stay in the same quintile of their marginal distribution as the quintile in the joint distribution. In the past fifty years, this probability for the women's second quintile has increased from 21.8 to 26.8 percent; for the third quintile, from 20.8 to 30.1 percent; for the fourth quintile, from 23.2 to 35.9 percent; and for the richest quintile, from 45.0 to 60.0 percent. These probabilities indicate an increase in rank-rank correlation between the women's and the joint distributions. Figure 2 shows the magnitude of changes for the women's bottom quintile in 1970 and in 2018. While 73.7 percent of women in the bottom quintile of their income distribution moved out of the bottom through marriage in 1970, only 56.0 percent do so in 2018. Conversely, while 45.0 percent of the highest-earning women stayed in that same earnings category as a couple, 60.0 percent do so in 2018.

Rank-rank correlations for the men have moved in the same direction, as for the women, for the three top-earnings quintiles but in the opposite direction for the bottom two quintiles. 
Table 4: Mobility-by-Marriage Probabilities

\begin{tabular}{|c|c|c|c|c|c|c|c|c|c|c|c|}
\hline \multirow{7}{*}{ 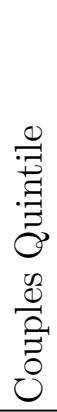 } & & \multicolumn{5}{|c|}{ Panel A: 1970 Men's Quintiles } & \multicolumn{5}{|c|}{ Panel B: 2018 Men's Quintiles } \\
\hline & & $1 \mathrm{st}$ & 2nd & 3rd & 4 th & 5 th & 1 st & 2nd & 3rd & 4 th & 5 th \\
\hline & 1 st & 79.30 & 20.71 & 0.00 & 0.00 & 0.00 & 69.86 & 30.17 & 0.00 & 0.00 & 0.00 \\
\hline & 2nd & 14.48 & 48.07 & 37.44 & 0.00 & 0.00 & 18.84 & 40.35 & 35.59 & 5.21 & 0.00 \\
\hline & $3 r d$ & 4.30 & 19.19 & 33.39 & 43.11 & 0.00 & 6.23 & 21.93 & 36.77 & 34.41 & 0.65 \\
\hline & 4 th & 1.57 & 10.65 & 21.53 & 37.27 & 28.99 & 3.37 & 5.94 & 23.31 & 41.48 & 25.90 \\
\hline & 5th & 0.34 & 1.38 & 7.64 & 19.62 & 71.01 & 1.71 & 1.62 & 4.32 & 18.90 & 73.45 \\
\hline \multirow{7}{*}{ 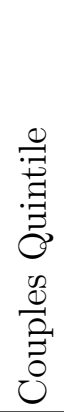 } & & \multicolumn{5}{|c|}{ Panel C: 1970 Women's Quintiles } & \multicolumn{5}{|c|}{ Panel D: 2018 Women's Quintiles } \\
\hline & & 1 st & 2nd & 3rd & 4 th & 5 th & 1st & 2nd & 3rd & 4 th & 5 th \\
\hline & 1st & 26.25 & 26.67 & 27.14 & 16.75 & 3.25 & 43.98 & 39.26 & 15.06 & 1.74 & 0.00 \\
\hline & 2nd & 23.39 & 21.82 & 25.24 & 22.16 & 7.37 & 23.34 & 26.75 & 33.40 & 14.30 & 2.19 \\
\hline & $3 \mathrm{rd}$ & 19.98 & 19.74 & 20.78 & 25.89 & 13.60 & 13.06 & 15.76 & 30.06 & 33.09 & 8.02 \\
\hline & 4 th & 15.35 & 15.70 & 14.88 & 23.26 & 30.80 & 9.72 & 10.16 & 14.41 & 35.90 & 29.80 \\
\hline & 5 th & 15.03 & 16.06 & 11.96 & 11.94 & 44.98 & 9.89 & 8.07 & 7.07 & 14.97 & 59.99 \\
\hline
\end{tabular}

Notes: This table lists the "mobility-by-marriage" probabilities of individuals (men: Panels A and B; women: Panels C and D) moving from their respective gender labor income quintiles to the couples labor income quintiles. Panels on the left represent probabilities for 1970, while panels on the right represent probabilities for 2018. The quintiles are ranked from the lowest, 1st, to the highest, 5 th. The diagonals in each panel represents the probability that the individual remains in the same quintile in the couples distribution as the quintile of their gender distribution. Source: Authors' calculation using IPUMS-CPS (https://cps.ipums.org/cps/). 
The probability that the men move from the bottom quintile of their marginal distribution to higher quintiles in the joint distribution has improved from 20.7 percent in 1970 to 30.1 percent in 2018. The top-earning men who remain in the top-earning quintile of the joint distribution have gone up slightly from 71.0 percent in 1970 to 73.3 percent in 2018. Also, note that the probability of staying in the same quintile for the men in all groups was higher than the women in 1970 and continues to do so in 2018. This indicates that the men's earnings position from their labor income distribution was a good indicator of their relative position in the joint distribution and continues to be so. Historically, men's earnings played a bigger role in the income of families. This is especially true for the top-earning men. Increasingly so, women's position in their gender distribution is predicting better their positions in the joint distribution.

What is rather unexpected is that for the men in the bottom quintile, marriage has now become a tool for upward mobility, whereas for women it is the opposite. While 21.7 percent of men moved out of their bottom quintile through marriage in 1970, 31.1 percent do so in 2018. Although these changes are in the opposite direction, they are not symmetric implying that despite the increase in the share of men moving out of the bottom, overall there are more individuals staying at the bottom through marriage in 2018 compared to 1970.

\subsubsection{Rank-rank associations between the marginal distributions}

As with the increase in rank-rank association between the marginal and joint distribution, there has also been an increase in the rank-rank association between the two marginal distributions. That is, increasingly so, men and women are married to individuals who are in a similar position as their marginal distributions as their partner. Table 5 lists the share of men and women in the top percentile (Panel A) and top decile (Panel B) of their gender's labor income distribution who are paired to individuals in various deciles of the opposite marginal distribution. The deciles are horizontally ranked from the poorest (p1p10) to the richest (p90p100). In 1970, 10.6 percent of men from the top decile in men's distribution were married to women from the top decile of the women's distribution (Panel B, column (10)), the same has increased to 23.3 percent in 2018. This has changed even more drastically for the top percentile of men's earners. In 1970, 10.2 percent married the top decile of women

earners (Panel A, column (10)), by 2018, 65.4 percent did the same. While this is true for the top percentile of men's earners, the share of the top percentile of women's earners married to the top decile of men decreased from 66.2 percent in 1970 to 41.4 in 2018.

In addition to the increasing trend in sorting over labor income at the top of the distribution, there has been a decline in the trend of higher-income men paired with lower-income women 
Figure 2: Mobility Probabilities for Women's Bottom and Top Quintiles in 1970 and 2018

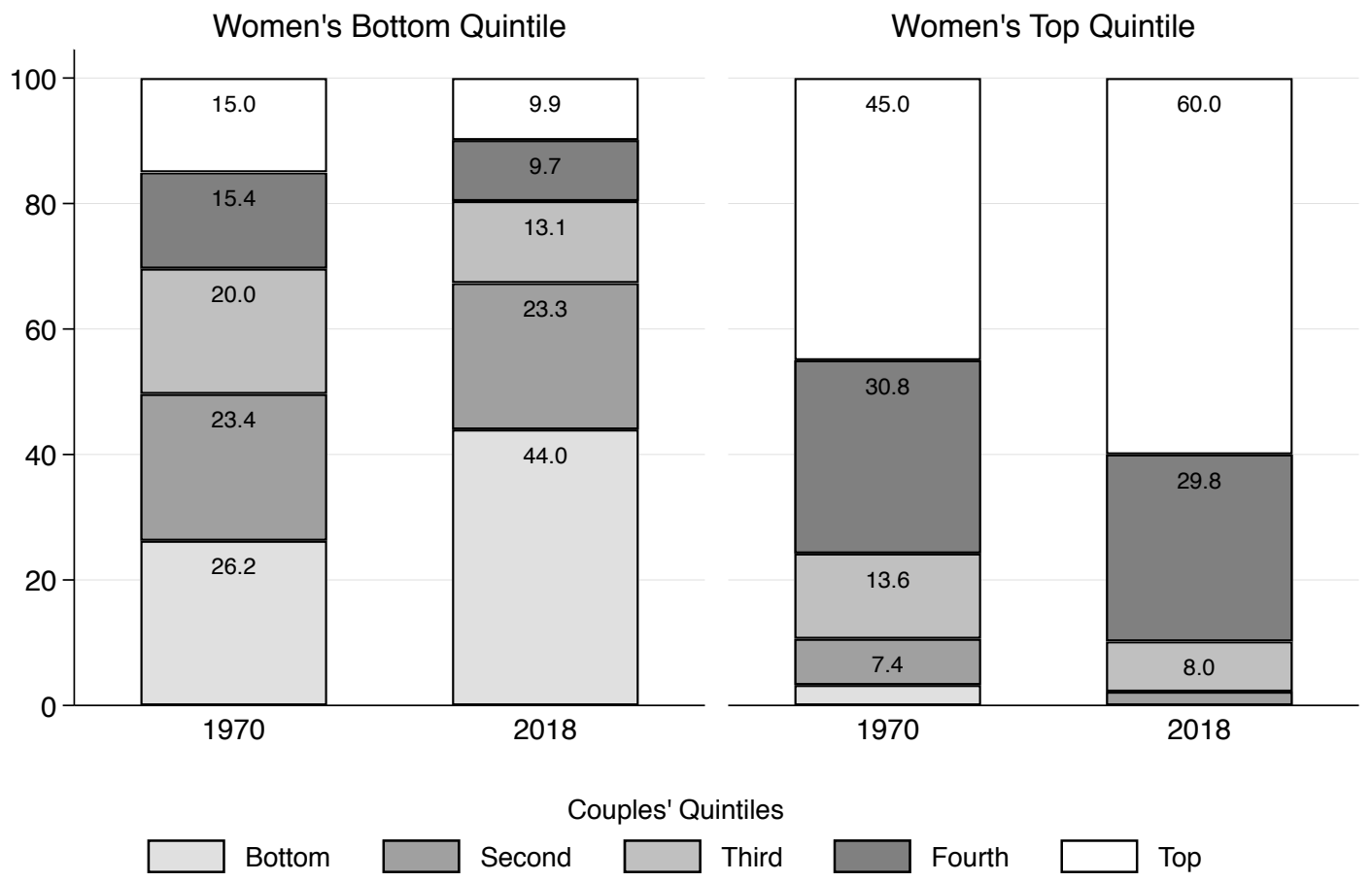

Notes: This chart shows the "mobility-by-marriage" probabilities of women moving from the bottom and the top labor income quintiles of women to the various couples labor income quintiles. The panel on the left shows the change in the probabilities for the bottom quintile from 1970 to 2018, while the panel on the right shows the change in the probabilities for the richest quintile in the same years. Each bar adds up to the total women in a particular quintile for each year. Each segment represents the share of the women from the quintile that move to various couples quintiles. The probabilities for the top female moving to the bottom couple quintile was 3.25 percent in 1970, and zero in 2018 (not reported in the figure). Source: See Panels C and D of Table 4. 
Table 5: Top Labor Earners Married to various Deciles of the opposite Marginal Distribution

\begin{tabular}{cccccccccc}
\hline$(1)$ & $(2)$ & $(3)$ & $(4)$ & $(5)$ & $(6)$ & $(7)$ & $(8)$ & $(9)$ & $(10)$ \\
$\mathrm{p} 1 \mathrm{p} 10$ & $\mathrm{p} 11 \mathrm{p} 20$ & $\mathrm{p} 21 \mathrm{p} 30$ & $\mathrm{p} 31 \mathrm{p} 40$ & $\mathrm{p} 41 \mathrm{p} 50$ & $\mathrm{p} 51 \mathrm{p} 60$ & $\mathrm{p} 61 \mathrm{p} 70$ & $\mathrm{p} 71 \mathrm{p} 80$ & $\mathrm{p} 81 \mathrm{p} 90$ & $\mathrm{p} 91 \mathrm{p} 100$ \\
\hline
\end{tabular}

Panel A: Top earning percentile married to various income deciles

\begin{tabular}{lcccccccccc} 
Men's Top 1\% & & & & & & & \\
1970 & 13.7 & 11.9 & 15.7 & 16.0 & 18.1 & 5.1 & 3.4 & 3.4 & 2.4 & 10.2 \\
1980 & 7.6 & 7.3 & 8.6 & 8.7 & 4.4 & 3.0 & 1.3 & 1.4 & 1.8 & 55.9 \\
1990 & 9.0 & 7.6 & 8.6 & 4.8 & 3.5 & 2.4 & 1.4 & 1.6 & 1.6 & 59.6 \\
2000 & 6.9 & 7.4 & 6.9 & 4.6 & 3.5 & 2.8 & 1.2 & 3.9 & 1.3 & 61.5 \\
2010 & 9.0 & 9.2 & 6.7 & 3.7 & 3.8 & 2.2 & 1.2 & 1.5 & 1.7 & 60.9 \\
2018 & 5.6 & 6.7 & 6.2 & 4.0 & 3.7 & 3.7 & 1.7 & 1.2 & 1.7 & 65.4 \\
\multicolumn{2}{l}{ Women's Top $1 \%$} & & & & & & & & \\
1970 & 4.9 & 3.5 & 3.5 & 3.3 & 4.9 & 3.1 & 2.1 & 4.9 & 3.7 & 66.2 \\
1980 & 3.7 & 2.8 & 2.8 & 3.0 & 3.8 & 3.1 & 1.8 & 4.8 & 3.8 & 70.3 \\
1990 & 3.1 & 2.4 & 5.1 & 4.4 & 4.7 & 4.1 & 2.0 & 6.4 & 8.5 & 59.3 \\
2000 & 4.0 & 2.9 & 1.8 & 2.9 & 2.4 & 3.7 & 1.7 & 3.5 & 2.6 & 74.4 \\
2010 & 4.7 & 3.4 & 2.9 & 2.3 & 2.8 & 4.1 & 1.8 & 3.2 & 2.6 & 72.1 \\
2018 & 10.6 & 4.7 & 5.0 & 5.3 & 5.6 & 8.1 & 5.0 & 6.9 & 7.5 & 41.4 \\
\hline
\end{tabular}

Panel B: Top earning decile married to various income deciles

\begin{tabular}{|c|c|c|c|c|c|c|c|c|c|c|}
\hline \multicolumn{11}{|c|}{ Men's Top 10\% } \\
\hline 1970 & 12.4 & 13.4 & 12.2 & 15.4 & 12.4 & 7.2 & 6.6 & 4.8 & 4.9 & 10.6 \\
\hline 1980 & 12.5 & 12.6 & 12.9 & 12.9 & 9.3 & 8.3 & 6.6 & 6.1 & 7.0 & 11.6 \\
\hline 1990 & 11.9 & 11.0 & 12.3 & 9.0 & 7.1 & 6.7 & 7.7 & 6.7 & 9.3 & 18.2 \\
\hline 2000 & 13.4 & 13.0 & 12.0 & 9.1 & 6.2 & 5.8 & 6.3 & 8.0 & 9.2 & 17.1 \\
\hline 2010 & 12.3 & 11.7 & 10.7 & 10.0 & 6.8 & 5.4 & 6.6 & 7.3 & 9.5 & 19.7 \\
\hline 2018 & 10.5 & 10.8 & 10.7 & 7.5 & 5.1 & 5.9 & 6.4 & 7.8 & 11.9 & 23.3 \\
\hline \multicolumn{11}{|c|}{ Women's Top $10 \%$} \\
\hline 1970 & 8.2 & 7.0 & 7.6 & 8.5 & 10.6 & 11.8 & 11.8 & 13.0 & 10.7 & 10.6 \\
\hline 1980 & 7.3 & 7.2 & 5.7 & 7.1 & 10.9 & 11.4 & 12.0 & 13.2 & 13.7 & 11.5 \\
\hline 1990 & 6.3 & 4.8 & 4.8 & 5.3 & 6.6 & 8.9 & 13.3 & 15.5 & 16.6 & 17.9 \\
\hline 2000 & 7.1 & 5.2 & 4.7 & 5.5 & 7.6 & 9.9 & 12.0 & 13.8 & 17.1 & 17.1 \\
\hline 2010 & 8.4 & 6.1 & 4.4 & 4.9 & 5.9 & 8.7 & 10.5 & 14.4 & 16.9 & 19.8 \\
\hline 2018 & 7.9 & 5.2 & 4.2 & 3.9 & 6.0 & 7.2 & 10.2 & 13.5 & 18.5 & 23.3 \\
\hline
\end{tabular}

Notes: This table lists the share of the men and women from the top earning percentile and the top earning decile of the gender distributions married to various income deciles in the opposite gender distribution. The income deciles are ranked form the lowest, p1p10, to the highest, p90p100. Reading: In 1970, 13.7 percent (column 1, row: Men's Top 1\% in 1970) of the top percentile of men from the men's labor income distribution were married to the women in the bottom decile of the women's labor income distribution. The share married to the top decile of women in the same year was 10.2 percent (column 10, row: Men's Top $1 \%$ in 1970). The shares in each year sum to 100 percent. Source: Authors' calculation using IPUMS-CPS (https://cps.ipums.org/cps/). 
and vice versa. Whereas in 1970, 12.4 percent of men from the men's top-earning decile were married to women from the women's bottom earning decile, this number has decreased to 10.5 percent in 2018. The corresponding share for the top decile of women's earners married to the men's bottom decile of earners was 8.2 percent in 1970 and 7.9 percent in 2018. Figures 3 and 4 show respectively these trends in the top-earning men's and women's deciles married to top and bottom earning deciles of the opposite marginal distributions. These trends in rank-rank association of the gender distributions are similar for the various age cohorts (see Tables A.4 and Figures A.4 - A.9).

Figure 3: Share of men from the men's top decile married to women from the top and bottom women's deciles

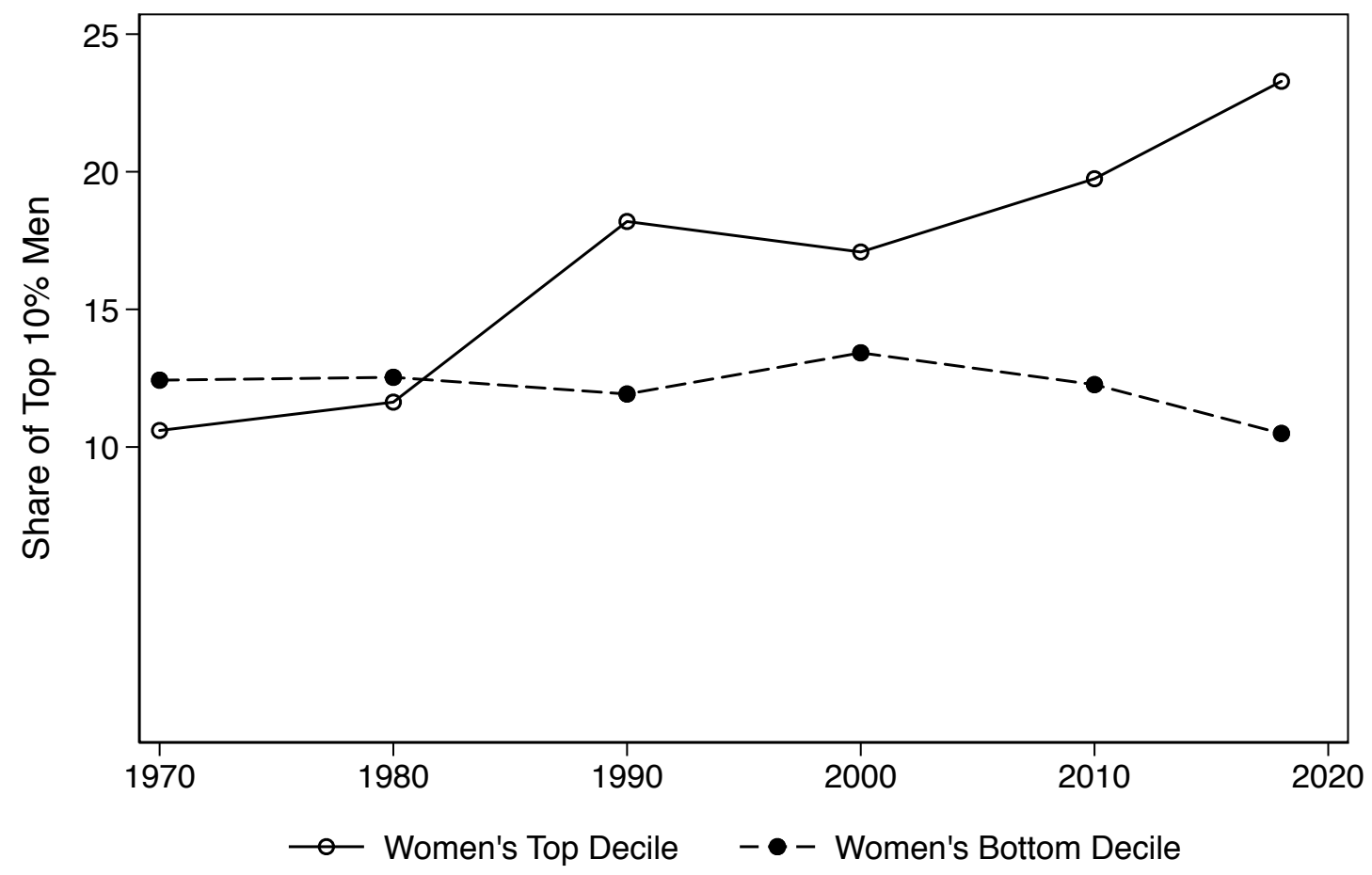

Notes: This figure shows the share (in percent) of men from the men's top labor income decile married to women from the top (solid line) and bottom (broken line) women's labor income deciles for the period 1970-2018. Source: Columns (1) and (10), Panel B in Table 5.

What is also interesting is that the rate at which the top percentile, and to a lesser extent the top decile, of each distribution, married the top decile of the opposite gender distribution was not only significantly higher than those who married the bottom deciles but that this share was also higher than the share married to the second top-earning decile. Column (9) of Table 5 reports the shares married to the second highest-earning decile (p81p90) and column (10) 
Figure 4: Share of women from the women's top decile married to men from the top and bottom men's deciles

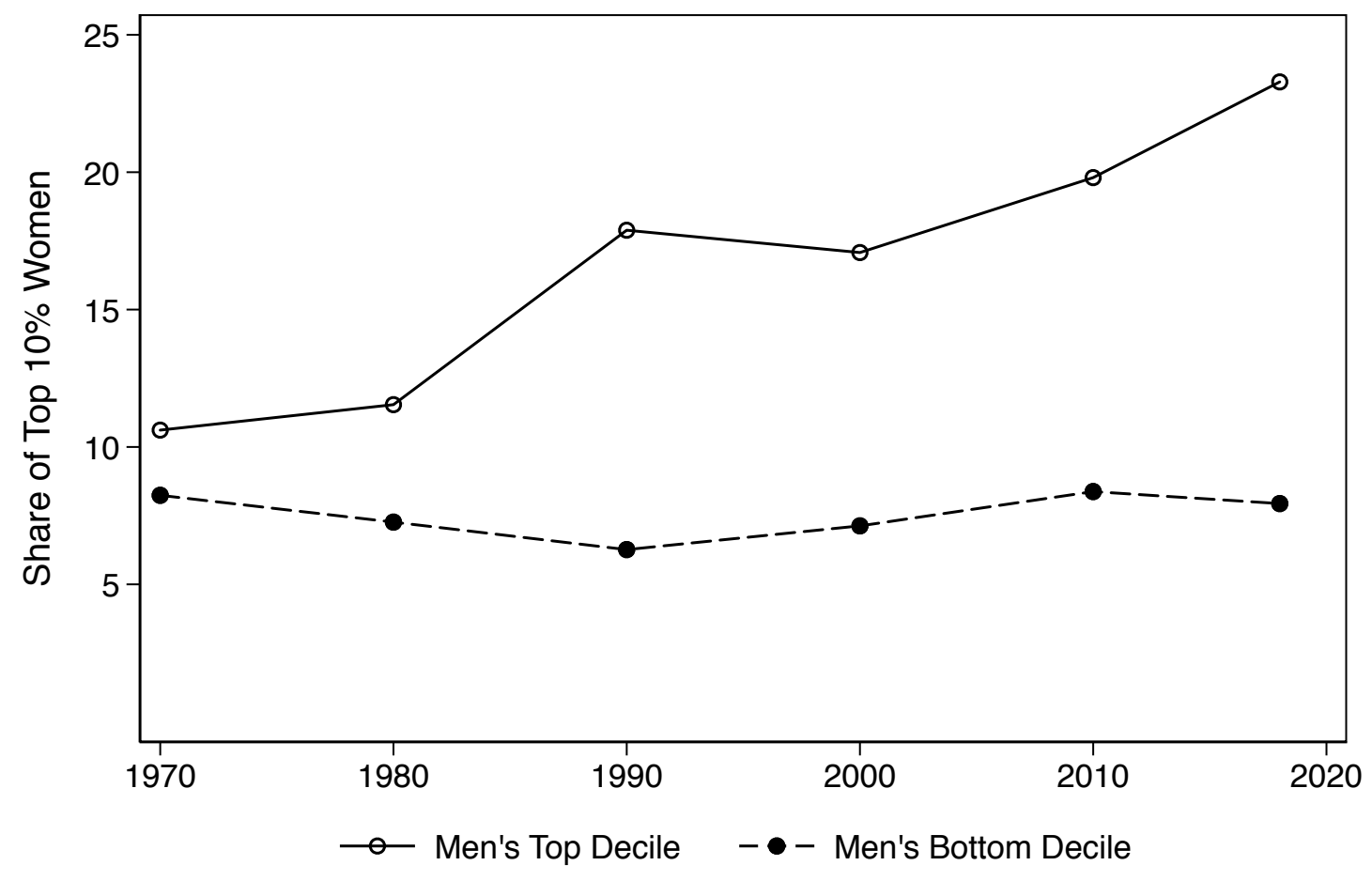

Notes: This figure shows the share (in percent) of women from the women's top labor income decile married to men from the top (solid line) and bottom (broken line) men's labor income deciles for the period 1970-2018. Source: Columns (1) and (10), Panel B in Table 5.

the shares married to the highest-earning decile (p91p100). The share of the highest-earning decile of the men married to the highest-earning decile of women was 2.1 fold higher in 1970 and has remained 1.9 folds higher in 2018. The changes in the women's top decile earners married to the highest and the second highest-earning men's deciles are even starker. While in 1970, the share of women from their top-earning decile married to the p91p100 men's decile was almost the same as those married to the next richest decile, in 2018, 1.26 more women are married to the richest decile.

Another way to think about the rank-rank correlation between gender distributions is to ask what, on average, is the rank of women that a man is married to. Figure 5 shows the average income position of women married to a man in each income percentile in 1970 and $2019 .{ }^{18}$ On average, a man in the highest-earning (100th) percentile was married to the 40th ranked

\footnotetext{
${ }^{18}$ Figure A.10 shows the median ranking women rather than the mean ranking woman.
} 
women in 1970 and the 53rd ranked women in 2018. It is also interesting to note that in 2018, relative to 1970, the whole distribution of rank-rank correlations between the marginal distributions has shifted more towards a comonotonic distribution, ${ }^{19}$ suggesting increased assortative mating over labor income.

Figure 5: Rank-rank correlation for each percentile in 1970 and 2018

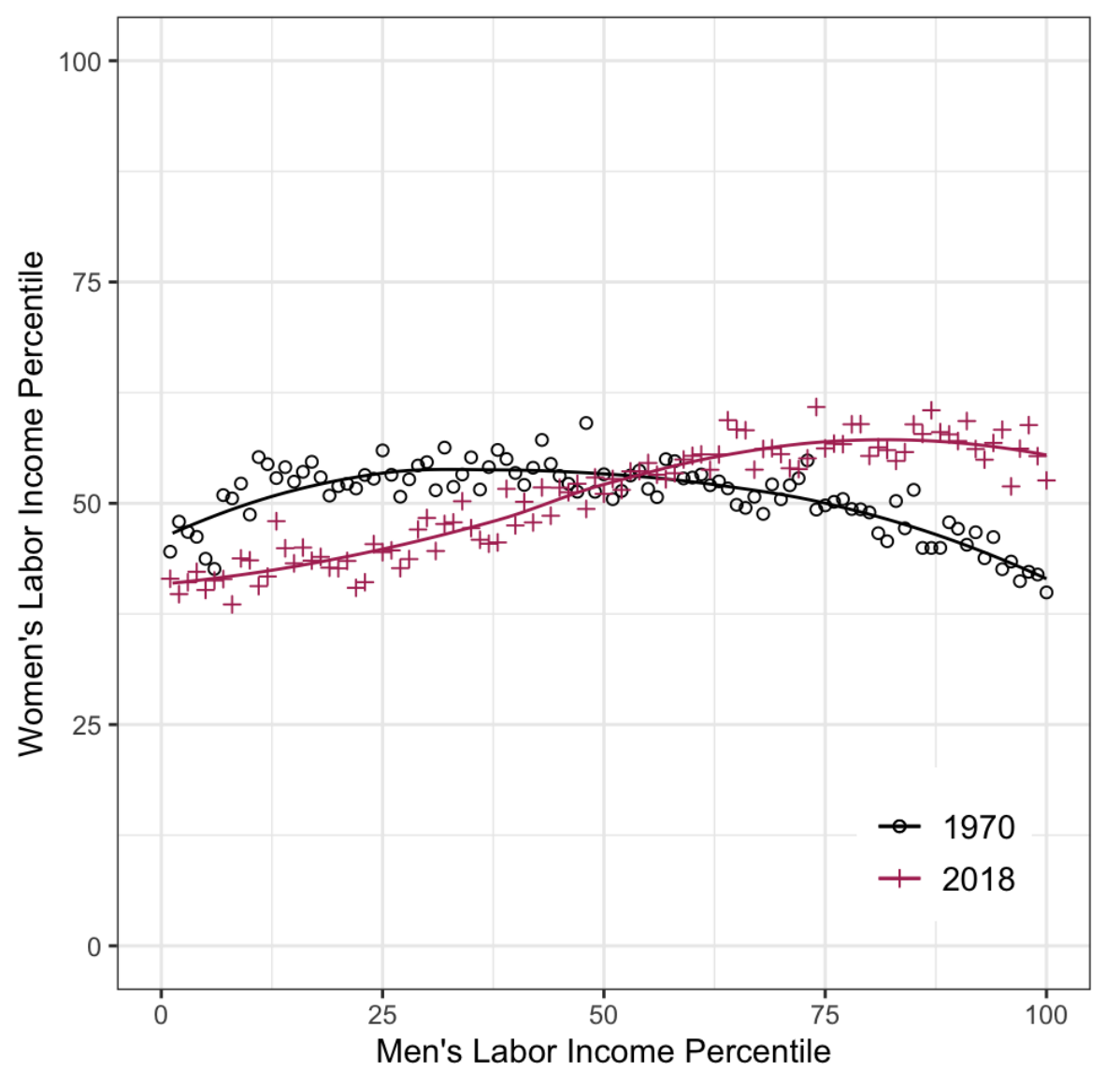

Notes: This figure shows the rank-rank correlation between each percentile of the marginal distributions in 1970 and 2018. For each percentile of the men's distribution, it shows the average rank of their partner in the women's distribution. The percentiles are ranked by each gender's labor income from the poorest percentile (left) to the richest percentile (right). A non-parametric regression line is fitted for each year. Source: Authors' calculation using IPUMS-CPS (https://cps.ipums.org/cps/).

\footnotetext{
${ }^{19}$ For a comparison to the extremes see Figure A.2. It shows a perfectly-paired (comonotonic) and an opposite-paired (countermonotonic) distribution.
} 


\subsection{Labor Income Inequality}

The evidence outlined above suggests that there has been an increasing trend in individuals sorting over labor income. There is more correlation between the marginal and the joint distributions, and also between the two marginal distributions. In what follows, I explore the effect of this increased assortative mating on labor income inequality.

\subsubsection{Trends in labor income inequality}

Income inequality as measured by the Gini coefficient as well as by the share of income earned by the top earners has increased for the men's as well as for the couples' distributions. Table 6 reports the Gini coefficient in column (1), and income shares of the top percentile of earners in column (2), the top five percent in column (3), and the top decile in column(4). Further, columns (5) and (6) of this table report the share of income held by the top five and top ten percentiles excluding the income of the top percentile. The Gini coefficient for the men's distribution has increased from 0.36 in 1970 to 0.51 in 2018. The 15-point increase in the Gini coefficient for the men's distribution tracks closely the 12-point increase in the Gini coefficient, from 0.33 to 0.45 , for the joint distribution. For the women, however, the Gini has decreased from 0.72 in 1970 to 0.60 in 2018. It is likely that the decline in Gini for the women is due to the increased labor force participation of women over the past fifty years. The income share of the top percentile of the income distribution has gone up for both the marginal distributions and also the joint distribution. The income share of the Top 1\% earners increased from 8.1 to 10.6 percent for the women, 4.8 to 10.9 for the men, and 4.2 to 8.6 for the joint distribution. While there was a universal increase in the income share of the top percentile of earners, the income share of the bottom nine percent of the top decile earners increased by 6.1 percentage points for the men, increased by 5.5 percentage points for the joint distribution, but decreased by 7.4 percentage points for the women. These changes help explain the decrease in dispersion, as measured by the Gini coefficient, in the women's distribution. Next, we look at the increase in inequality of the couples' distribution relative to the upper and lower bounds.

\subsubsection{Inequality relative to Frechet-Heoffding bounds}

The Frechet-Heoffding bounds provide us with a baseline to compare the changes in labor income inequality of the joint distribution. In particular, the comonotonic (perfect-pair) and the countermonotonic (opposite-pair) copulas give us the upper and lower bounds of 
Table 6: Trends in Labor Income Inequality

\begin{tabular}{|c|c|c|c|c|c|c|}
\hline & $\begin{array}{c}(1) \\
\text { Gini }\end{array}$ & $\begin{array}{c}(2) \\
\text { Top } 1 \%\end{array}$ & $\begin{array}{c}(3) \\
\text { Top } 5 \%\end{array}$ & $\begin{array}{c}(4) \\
\text { Top } 10 \%\end{array}$ & $\begin{array}{c}(5) \\
\text { Top } 5-1 \%\end{array}$ & $\begin{array}{c}(6) \\
\text { Top 10-1\% }\end{array}$ \\
\hline \multicolumn{7}{|c|}{ Panel A: Joint Distribution } \\
\hline 1970 & 0.33 & 4.2 & 14.2 & 23.4 & 10.0 & 19.3 \\
\hline 1980 & 0.36 & 4.4 & 15.1 & 25.2 & 10.7 & 20.8 \\
\hline 1990 & 0.40 & 5.8 & 17.4 & 28.0 & 11.6 & 22.2 \\
\hline 2000 & 0.44 & 9.6 & 23.8 & 34.0 & 14.2 & 24.4 \\
\hline 2010 & 0.45 & 7.8 & 20.6 & 31.4 & 12.8 & 23.6 \\
\hline 2018 & 0.45 & 8.6 & 22.2 & 33.3 & 13.6 & 24.7 \\
\hline $1970-2018$ & 0.12 & 4.4 & 8.0 & 9.9 & 3.6 & 5.5 \\
\hline \multicolumn{7}{|c|}{ Panel B: Men's Distribution } \\
\hline 1970 & 0.36 & 4.8 & 15.7 & 25.2 & 10.9 & 20.5 \\
\hline 1980 & 0.41 & 5.5 & 17.1 & 27.8 & 11.7 & 22.3 \\
\hline 1990 & 0.45 & 7.4 & 20.4 & 31.3 & 13.0 & 23.8 \\
\hline 2000 & 0.51 & 11.8 & 28.3 & 38.6 & 16.4 & 26.8 \\
\hline 2010 & 0.53 & 10.3 & 24.7 & 36.4 & 14.5 & 26.1 \\
\hline 2018 & 0.51 & 10.9 & 25.8 & 37.5 & 14.9 & 26.6 \\
\hline $1970-2018$ & 0.15 & 6.1 & 10.1 & 12.2 & 4.0 & 6.1 \\
\hline \multicolumn{7}{|c|}{ Panel C: Women's Distribution } \\
\hline 1970 & 0.72 & 8.1 & 27.1 & 45.3 & 19.1 & 37.3 \\
\hline 1980 & 0.65 & 6.8 & 23.8 & 39.9 & 17.0 & 33.1 \\
\hline 1990 & 0.60 & 7.2 & 23.2 & 37.3 & 16.0 & 30.1 \\
\hline 2000 & 0.58 & 10.3 & 25.7 & 38.7 & 15.4 & 28.4 \\
\hline 2010 & 0.60 & 8.7 & 24.8 & 38.5 & 16.1 & 29.8 \\
\hline 2018 & 0.60 & 10.6 & 26.9 & 40.4 & 16.3 & 29.8 \\
\hline $1970-2018$ & -0.12 & 2.5 & -0.2 & -4.9 & -2.7 & -7.4 \\
\hline
\end{tabular}

Notes: This table reports labor income inequality of the current joint and marginal distributions. The Gini coefficient ranges from zero, most equal, to one, most unequal. Top 1\%, $5 \%$, and $10 \%$ measures the share of labor income held by the top percentile, the top five percentiles, and the top decile of earners. Top 5-1\% (10-1\%) captures income of the top five (ten) excluding the very top percentile of income earners. Source: Authors' calculation using IPUMS-CPS (https://cps.ipums.org/cps/). 
possible labor income inequality using the current level of labor income. Panel A of Table 7 replicates the inequality measures of the joint distribution from Table 6. Further, it reports the inequality in the perfect-pair distribution in Panel B and the inequality in the opposite-pair distribution in Panel C. Interestingly, the changes in the inequality measures of the current joint distribution followed very closely the changes in inequality measures of the perfectly-paired distribution. While less matching in trends, the inequality of the opposite-paired distribution, nevertheless, moved in the same direction.

Overall, the Gini coefficient increased by 12 points for the joint distribution as well as for the perfectly-paired distribution, while it went up by 4 points for the opposite-paired distribution in the past fifty years. The share of income for the top percentile of earners increased by 4.4 percentage points for the joint distribution, 5.7 percentage points for the perfect-pair distribution, and 3.5 percentage points for the opposite-pair distribution. The share of income of the bottom nine percentiles of the top decile rose by 5.5, 4.6, and 1.3 percentage points respectively for the joint, perfect-pair, and opposite pair distributions.

Panel A of Figure 6 shows the trends in the Gini coefficient for these three distributions. An increase in inequality due to positive sorting would suggest the Gini of the joint distribution move closer to that of the perfect-pair distribution or move away from the Gini of the opposite-pair distribution. To that end, Panel B shows the percent increase in Gini coefficient from the lower bound (dark bars) and the percent decrease from the upper bound (light bars). While the gap between the current joint distribution and the opposite-pair distribution increased from 74 percent in 1970 to 93 percent in 2018, most of this increase was accounted for in the first three decades of the study. Indeed, from 1990 to 2018, the percent gap from the bottom to the current joint distribution decreased 7 percentage points. Similar trends can also be seen in the gap between the joint distribution and the upper bound. This gap from the top decreased from 21 percent in 1970 to 18 percent in 1990, it has remained stable since. ${ }^{20}$ On the other hand, the Gini coefficient of the joint distribution rose from 7 points in the 1970-1990 period, and further from 5 points in the 1990-2018 period. Similarly, the share of income held by the top-earning percentile of the same rose 1.6 percentage points in the 1970-1990 period and a further 2.8 percentage points in the 1990-2018 period. In other words, while inequality of the joint distribution continued to increase at a similar rate before and after 1990, the movement in inequality due to labor-income sorting remained stable in the period after 1990 .

While labor income inequality among couples has increased in the past fifty years, there is

\footnotetext{
${ }^{20}$ These trends are consistent when using the other measures of income inequality (for example see Figure A.11).
} 
Table 7: Labor Income Inequality relative to the Frechet-Heoffding bounds

\begin{tabular}{ccccccc}
\hline & $(1)$ & $(2)$ & $(3)$ & $(4)$ & $(5)$ & $(6)$ \\
& Gini & Top 1\% & Top 5\% & Top 10\% & Top 5-1\% & Top 10-1\% \\
\hline \multicolumn{7}{c}{ Panel A: Joint Distribution } \\
1970 & 0.33 & 4.2 & 14.2 & 23.4 & 10.0 & 19.3 \\
1980 & 0.36 & 4.4 & 15.1 & 25.2 & 10.7 & 20.8 \\
1990 & 0.40 & 5.8 & 17.4 & 28.0 & 11.6 & 22.2 \\
2000 & 0.44 & 9.6 & 23.8 & 34.0 & 14.2 & 24.4 \\
2010 & 0.45 & 7.8 & 20.6 & 31.4 & 12.8 & 23.6 \\
2018 & 0.45 & 8.6 & 22.2 & 33.3 & 13.6 & 24.7 \\
\hline $1970-2018$ & 0.12 & 4.4 & 8.0 & 9.9 & 3.6 & 5.5 \\
\hline
\end{tabular}

\begin{tabular}{ccccccc}
\multicolumn{7}{c}{ Panel B: Perfect-Pair Distribution (upper bound) } \\
1970 & 0.42 & 5.3 & 17.6 & 28.5 & 12.2 & 23.2 \\
1980 & 0.46 & 5.9 & 18.5 & 30.2 & 12.6 & 24.3 \\
1990 & 0.49 & 7.4 & 21.0 & 32.7 & 13.7 & 25.3 \\
2000 & 0.53 & 11.8 & 27.3 & 38.5 & 15.6 & 26.7 \\
2010 & 0.55 & 10.0 & 24.8 & 37.0 & 14.8 & 27.1 \\
2018 & 0.54 & 11.0 & 26.5 & 38.8 & 15.5 & 27.8 \\
\hline $1970-2018$ & 0.12 & 5.7 & 8.9 & 10.3 & 3.2 & 4.6 \\
\hline \multicolumn{7}{c}{ Panel C: Opposite-Pair Distribution (lower bound) } \\
1970 & 0.19 & 4.1 & 13.2 & 21.3 & 9.1 & 17.2 \\
1980 & 0.20 & 4.0 & 13.1 & 21.2 & 9.0 & 17.2 \\
1990 & 0.20 & 5.3 & 14.5 & 22.4 & 9.3 & 17.2 \\
2000 & 0.25 & 8.4 & 20.3 & 27.8 & 11.9 & 19.5 \\
2010 & 0.23 & 6.7 & 16.9 & 25.3 & 10.2 & 18.6 \\
2018 & 0.23 & 7.6 & 18.0 & 26.1 & 10.3 & 18.5 \\
\hline $1970-2018$ & 0.04 & 3.5 & 4.7 & 4.8 & 1.2 & 1.3 \\
\hline \hline
\end{tabular}

Notes: This table reports labor income inequality of the current joint distribution and that of the counterfactual joint distributions. The Gini coefficient ranges from zero, most equal, to one, most unequal. Top 1\%, $5 \%$, and $10 \%$ measures the share of labor income held by the top percentile, the top five percentiles, and the top decile of earners. Top 5-1\% (10-1\%) captures income of the top five (ten) excluding the very top percentile of income earners. Source: Authors' calculation using IPUMS-CPS (https://cps.ipums.org/cps/). 
Figure 6: Inequality Relative to the Bounds
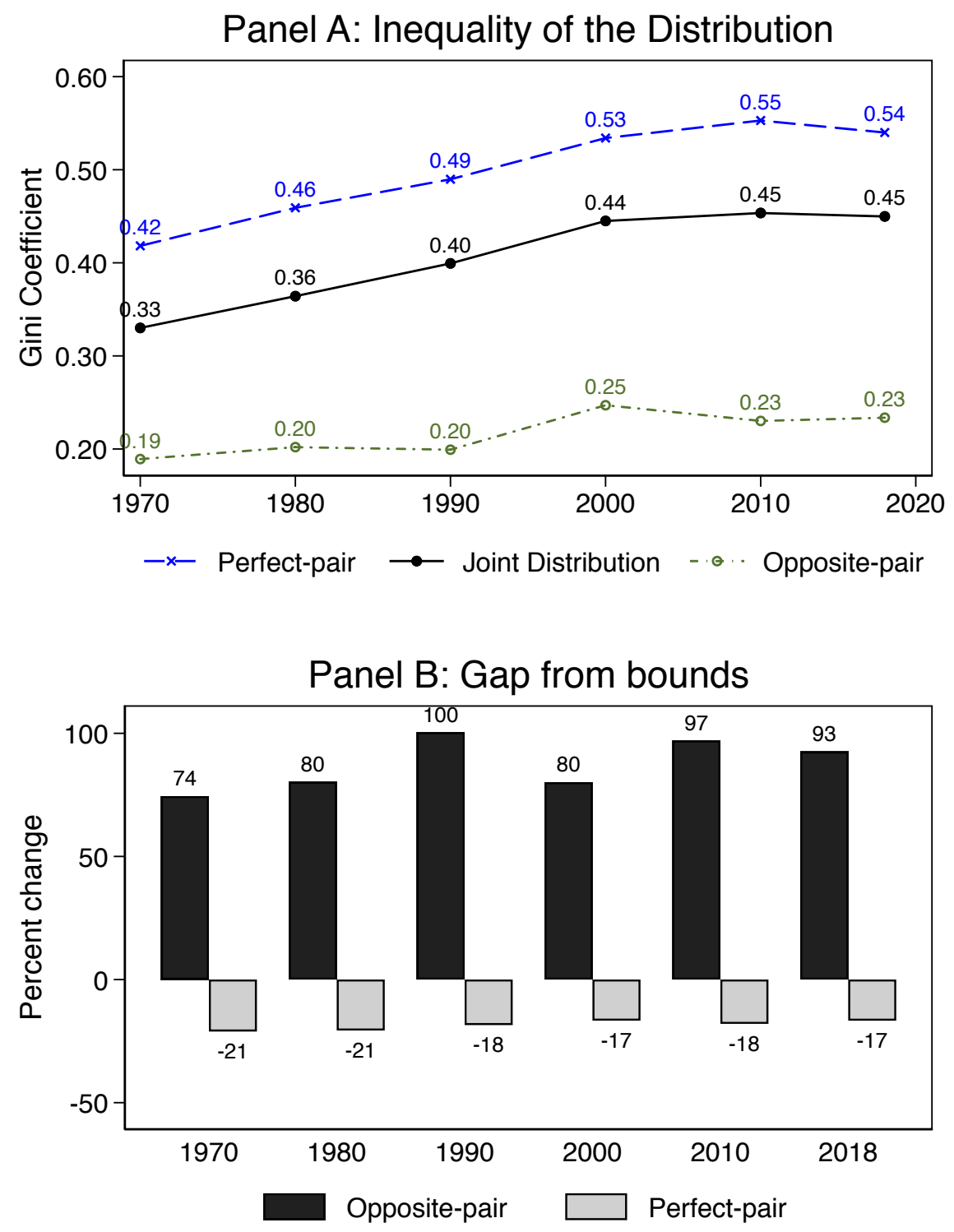

Notes: Panel A of this figure shows the trends in Gini coefficient for the current joint distribution and the perfect-pair (upper-bound for inequality) and opposite-paired (lower-bound for inequality) distributions. Panel $\mathrm{B}$ shows the trend in the percent increase (decrease) in Gini coefficient of the current joint distribution from the lower (upper) bound. Source: Authors' calculation using IPUMS-CPS (https://cps.ipums.org/cps/). 
little to suggest that this is entirely due to positive sorting over labor income. There was an increase in inequality due to sorting in the 1970-1990 period, but since then, the effect due to sorting has been minimal. The increase in inequality of the joint distribution after 1990 is perhaps due to the underlying increase in inequality of labor earnings or other factors and not due to the sorting mechanism. This can be seen as the inequality trends of the current joint distribution mimics the changes in inequality in the perfect-pair distribution in the 1990-2018 period; that is, the shortfall from the maximum inequality constantly remains between 17 and 18 percent as seen in Panel B of Figure 6 (light-colored bars). Note that this shortfall decreased by 14 percent in the 1970-1990 period.

\section{Conclusion}

This paper has two significant contributions to the literature. First, I find that the correlation between labor income within couples has increased over the past fifty years. While only twenty-four percent of the income of the top-earning percentile of women were accounted for in the income of the top-earning percentile of couples in 1970, fifty-five percent of it was accounted for in 2018. On the other hand, top-earning men's share of income accounted for in the joint distribution has only slightly declined from 87 percent in 1970 to 82 percent in 2018 . The correlations between the gender distributions and the joint distribution have increased not only at the top of the income distribution but also at the bottom of the distribution. Focusing on the correlation of income ranks between the marginal and joint distribution, I find that 73.8 percent of women in the bottom quintile of their income distribution moved out to higher quintiles through marriage in 1970, and 56.0 percent of them did so in 2018. That is, in the last fifty years 18 percentage points more women from the lowest-earning women's quintile stay in the bottom earning quintile after marriage. In the same time period, the share of the top-earning quintile of women staying in the top-earning quintile of the couples increased by 15 percentage points.

Not only has there been an increase in income correlation between the marginal and joint distributions, but there has also been an increase in the rank-rank correlation between the two marginal gender distributions. In 1970, 10.6 percent of the top-earning decile of men were married to the top-earning decile of women. This has more than doubled to 23.3 percent in 2018. At the same time, the top-earning decile of men married to the bottom earning decile of women has decreased from 12.4 percent to 10.5 percent. This decline is also reflected in the top-earning decile of women married to the bottom earning decile of men - from 8.2 percent in 1970 to 7.9 percent in 2018. Overall, the correlation of the entire labor income distribution 
of couples has shifted more towards a comonotonic copula (perfect-pair) distribution in 2018 as compared to the distribution in 1970.

Second, while labor income correlation between the marginal and joint distributions has increased, its link to the increase in labor income inequality of the joint distribution is not that clear. Labor income inequality among couples has increased, as measured by the Gini coefficient, by 33 percent in the last fifty years. Inequality of the joint distribution moved away from the inequality of the opposite-pair distribution (that is the distribution with the lowest possible inequality given the current labor market behavior of married individuals) and towards the inequality of the perfect-pair distribution (that is the distribution with the highest possible inequality given the current labor market behavior of married individuals) in the 1970-1990 period - suggesting a positive role of couples sorting over labor income on the increases in labor income inequality in this period. For instance, in 1970-1990, the inequality of the joint distribution moved closer to the maximum possible inequality (that is the inequality in the perfectly-paired distribution) by 14 percent. In the same period, the Gini coefficient of the joint distribution increased by 7 points. However, the gap between the joint and perfect-pair distributions was constant in the 1990-2018 period, while the Gini coefficient of the joint distribution rose by 5 points. This suggests that coupling over labor income has little if any, role in the increases in labor income inequality of the joint distribution in the period after 1990. The drivers of the increases in labor income inequality of the perfect-pair and opposite-pair distributions over the last three decades are likely to be responsible for the increases in inequality of the current joint distribution and not the positive sorting over labor income. 


\section{References}

Aaberge, Rolf, Anthony B Atkinson, and Sebastian Königs. 2018. "From Classes to Copulas: Wages, Capital, and Top Incomes." The Journal of Economic Inequality 16 (2). Springer: 295-320.

Atkinson, Anthony B. 2007. "Measuring Top Incomes: Methodological Issues." Top Incomes over the Twentieth Century: A Contrast Between Continental European and English-Speaking Countries 1. Oxford University Press New York: 18-42.

Atkinson, Anthony B, and Christoph Lakner. 2017. "Capital and Labor: The Factor Income Composition of Top Incomes in the United States, 1962-2006." The World Bank.

Becker, Gary S. 1973. "A Theory of Marriage: Part I." Journal of Political Economy 81 (4): 813-46. doi:10.1086/260084.

Bloome, Deirdre, Derek Burk, and Leslie McCall. 2019. "Economic Self-Reliance and Gender Inequality Between Us Men and Women, 1970-2010." American Journal of Sociology 124 (5). The University of Chicago Press Chicago, IL: 1413-67.

Bø, Erlend E, Peter J Lambert, and Thor O Thoresen. 2012. "Horizontal Inequity Under a Dual Income Tax System: Principles and Measurement." International Tax and Public Finance 19 (5). Springer: 625-40.

Cancian, Maria, and Deborah Reed. 1998. "Assessing the Effects of Wives' Earnings on Family Income Inequality." The Review of Economics and Statistics 80 (1): 73-79. doi:10.1162/003465398557348.

Chetty, Raj, Nathaniel Hendren, Patrick Kline, Emmanuel Saez, and Nicholas Turner. 2014. "Is the United States Still a Land of Opportunity? Recent Trends in Intergenerational Mobility." American Economic Review 104 (5): 141-47.

Chiappori, Pierre-André, Bernard Salanié, and Yoram Weiss. 2017. "Partner Choice, Investment in Children, and the Marital College Premium." American Economic Review 107 (8): 2109-67.

Choo, Eugene, and Aloysius Siow. 2006. "Who Marries Whom and Why." Journal of Political Economy 114 (1). The University of Chicago Press: 175-201.

Dardanoni, Valentino, and Peter Lambert. 2001. "Horizontal Inequity Comparisons." Social Choice and Welfare 18 (4). Springer: 799-816.

Dupuy, Arnaud, and Alfred Galichon. 2014. "Personality Traits and the Marriage Market." 
Journal of Political Economy 122 (6). University of Chicago Press Chicago, IL: 1271-1319. Dupuy, Arnaud, and Simon Weber. 2019. "Marital Patterns and Income Inequality." Available at SSRN 3156484. https://papers.ssrn.com/sol3/papers.cfm?abstract_id=3156484.

Eika, Lasse, Magne Mogstad, and Basit Zafar. 2019. "Educational Assortative Mating and Household Income Inequality." Journal of Political Economy 127 (6). The University of Chicago Press Chicago, IL: 2795-2835.

Fiorio, Carlo V, and Stefano Verzillo. 2018. "Looking in Your Partner's Pocket Before Saying "Yes!" Income Assortative Mating and Inequality," no. (No. 2018-02). http://wp.demm.unimi. it/files/wp/2018/DEMM-2018_02wp.pdf.

Gihleb, Rania, and Kevin Lang. 2016. "Educational Homogamy and Assortative Mating Have Not Increased," no. NBER Working Papers No. 22927. https://www.nber.org/papers/ w22927.

Goldin, Claudia. 2006. "The Quiet Revolution That Transformed Women's Employment, Education, and Family." American Economic Review 96 (2): 1-21.

Gonalons-Pons, Pilar, and Christine R Schwartz. 2017. "Trends in Economic Homogamy: Changes in Assortative Mating or the Division of Labor in Marriage?" Demography 54 (3). Springer: $985-1005$.

Greenwood, Jeremy, Nezih Guner, Georgi Kocharkov, and Cezar Santos. 2014. "Marry Your Like: Assortative Mating and Income Inequality." American Economic Review 104 (5): 348-53. doi:10.1257/aer.104.5.348.

Hryshko, Dmytro, Chinhui Juhn, and Kristin McCue. 2017. "Trends in Earnings Inequality and Earnings Instability Among U.S. Couples: How Important Is Assortative Matching?" Labour Economics 48: 168-82. doi:https://doi.org/10.1016/j.labeco.2017.08.006.

Jepsen, Lisa K. 2005. "The Relationship Between Wife's Education and Husband's Earnings: Evidence from 1960 to 2000." Review of Economics of the Household 3 (2). Springer: 197-214. Larrimore, Jeff. 2014. "Accounting for United States Household Income Inequality Trends: The Changing Importance of Household Structure and Male and Female Labor Earnings Inequality." Review of Income and Wealth 60 (4). Wiley Online Library: 683-701.

Larrimore, Jeff, Richard V. Burkhauser, Shuaizhang Feng, and Laura Zayatz. 2008. "Consistent Cell Means for Topcoded Incomes in the Public Use March Cps (1976-2007)." Journal of Economic and Social Measurement 2/3 (33): 89-128. https://content.iospress.com/articles/ 
journal-of-economic-and-social-measurement/jem00299.

McCall, Leslie, and Christine Percheski. 2010. "Income Inequality: New Trends and Research Directions." Annual Review of Sociology 36. Annual Reviews: 329-47.

Nelsen, Roger B. 1999. "An Introduction to Copulas. New York, Usa." Lecture Notes in Statistics.

—. 2007. An Introduction to Copulas. Springer Science \& Business Media.

OECD. 2011. An Overview of Growing Income Inequalities in Oecd Countries: Main Findings. Divided We Stand: Why Inequality Keeps Rising, OECD publishing, Paris. http://www.oecd.org/els/soc/49499779.pdf.

Oppenheimer, Valerie Kincade. 1994. "Women's Rising Employment and the Future of the Family in Industrial Societies." Population and Development Review. JSTOR, 293-342.

Pencavel, John. 1998. "Assortative Mating by Schooling and the Work Behavior of Wives and Husbands." The American Economic Review 88 (2). JSTOR: 326-29.

Pestel, N. 2016. "Marital Sorting, Inequality and the Role of Female Labour Supply: Evidence from East and West Germany." Economica 333 (84): 104-27. doi:10.1111/ecca.12189.

Quinn, Casey. 2009. Measuring Income-Related Inequalities in Health Using a Parametric Dependence Function. University of York, Centre for Health Economics.

Reed, Deborah, and Maria Cancian. 2012. "Rising Family Income Inequality: The Importance of Sorting." Journal of Income Distribution 21 (2). Ad libros publications inc.: 3-14.

Sarah Flood, Steven Ruggles, Miriam King, and J. Robert Warren. 2017. "Integrated Public Use Microdata Series, Current Population Survey: Version 5.0." Minneapolis: University of Minnesota. doi:10.18128/D030.V5.0.

Schwartz, Christine R, and Robert D Mare. 2005. "Trends in Educational Assortative Marriage from 1940 to 2003." Demography 42 (4). Springer: 621-46.

Stevenson, Betsey, and Justin Wolfers. 2007. "Marriage and Divorce: Changes and Their Driving Forces." Journal of Economic Perspectives 21 (2): 27-52.

Western, Bruce, Deirdre Bloome, and Christine Percheski. 2008. "Inequality Among American Families with Children, 1975 to 2005." American Sociological Review 73 (6). Sage Publications Sage CA: Los Angeles, CA: 903-20.

Yavorsky, Jill E, Lisa A Keister, Yue Qian, and Michael Nau. 2019. "Women in the One Percent: Gender Dynamics in Top Income Positions." American Sociological Review 84 (1). SAGE Publications Sage CA: Los Angeles, CA: 54-81. 


\section{A Appendix Tables and Figures}

Table A.1: Alignment Coefficent, 20-35 age group

\begin{tabular}{lcccccc}
\hline & $(1)$ & $(2)$ & $(3)$ & $(4)$ & $(5)$ & $(6)$ \\
& 1970 & 1980 & 1990 & 2000 & 2010 & 2018 \\
\hline \multicolumn{7}{c}{ Panel A: Men } \\
Top 1\% & 0.74 & 0.70 & 0.82 & 0.89 & 0.78 & 0.81 \\
Top 5\% & 0.68 & 0.66 & 0.70 & 0.77 & 0.72 & 0.78 \\
Top 10\% & 0.67 & 0.64 & 0.70 & 0.78 & 0.72 & 0.77 \\
Top 5-1\% & 0.48 & 0.44 & 0.47 & 0.57 & 0.50 & 0.56 \\
Top 10-1\% & 0.56 & 0.53 & 0.57 & 0.67 & 0.60 & 0.64 \\
Middle 40\% & 0.67 & 0.67 & 0.69 & 0.70 & 0.70 & 0.71 \\
Bottom 50\% & 0.77 & 0.76 & 0.77 & 0.76 & 0.76 & 0.77 \\
\hline & \multicolumn{7}{c}{ Panel B: Women } \\
Top 1\% & 0.41 & 0.39 & 0.33 & 0.51 & 0.51 & 0.60 \\
Top 5\% & 0.40 & 0.48 & 0.56 & 0.61 & 0.63 & 0.66 \\
Top 10\% & 0.45 & 0.52 & 0.62 & 0.64 & 0.66 & 0.72 \\
Top 5-1\% & 0.23 & 0.30 & 0.40 & 0.36 & 0.42 & 0.39 \\
Top 10-1\% & 0.35 & 0.42 & 0.52 & 0.48 & 0.53 & 0.58 \\
Middle 40\% & 0.53 & 0.57 & 0.63 & 0.64 & 0.65 & 0.67 \\
Bottom 50\% & 0.65 & 0.67 & 0.72 & 0.73 & 0.71 & 0.76 \\
\hline \hline
\end{tabular}

Notes: $\alpha_{i g}$ measures the income association between the gender distribution and the joint distribution for 20-35 age group. For detail see Equation 5. Top 1\%, 5\%, and 10\% report income shares held by those income groups in each income distribution. Top 5-1\% (10-1\%) is the income group that represents income of the top 5 (top 10) percent income earners excluding the income of the very top percentile. Source: Authors' calculation using IPUMS-CPS (https://cps.ipums.org/cps/). 
Table A.2: Alignment Coefficent, 36-50 age group

\begin{tabular}{lcccccc}
\hline & $(1)$ & $(2)$ & $(3)$ & $(4)$ & $(5)$ & $(6)$ \\
& 1970 & 1980 & 1990 & 2000 & 2010 & 2018 \\
\hline \multicolumn{7}{c}{ Panel A: Men } \\
\cline { 2 - 7 } Top 1\% & 0.88 & 0.90 & 0.88 & 0.79 & 0.83 & 0.77 \\
Top 5\% & 0.84 & 0.80 & 0.79 & 0.88 & 0.80 & 0.76 \\
Top 10\% & 0.79 & 0.78 & 0.79 & 0.84 & 0.77 & 0.77 \\
Top 5-1\% & 0.75 & 0.69 & 0.65 & 0.75 & 0.64 & 0.55 \\
Top 10-1\% & 0.73 & 0.72 & 0.71 & 0.74 & 0.67 & 0.65 \\
Middle 40\% & 0.74 & 0.76 & 0.73 & 0.72 & 0.73 & 0.72 \\
Bottom 50\% & 0.78 & 0.77 & 0.75 & 0.75 & 0.77 & 0.78 \\
\hline & & & Panel B: Women & \\
Top 1\% & 0.16 & 0.15 & 0.31 & 0.53 & 0.43 & 0.49 \\
Top 5\% & 0.28 & 0.30 & 0.44 & 0.50 & 0.52 & 0.62 \\
Top 10\% & 0.39 & 0.40 & 0.49 & 0.56 & 0.60 & 0.66 \\
Top 5-1\% & 0.13 & 0.13 & 0.23 & 0.16 & 0.26 & 0.37 \\
Top 10-1\% & 0.29 & 0.28 & 0.35 & 0.36 & 0.46 & 0.51 \\
Middle 40\% & 0.54 & 0.54 & 0.58 & 0.60 & 0.63 & 0.64 \\
Bottom 50\% & 0.65 & 0.63 & 0.69 & 0.68 & 0.71 & 0.73 \\
\hline \hline
\end{tabular}

Notes: $\alpha_{i g}$ measures the income association between the gender distribution and the joint distribution for 36-50 age group. For detail see Equation 5. Top 1\%, 5\%, and 10\% report income shares held by those income groups in each income distribution. Top 5-1\% (10-1\%) is the income group that represents income of the top 5 (top 10) percent income earners excluding the income of the very top percentile. Source: Authors' calculation using IPUMS-CPS (https://cps.ipums.org/cps/). 
Table A.3: Alignment Coefficent, 51-65 age group

\begin{tabular}{lcccccc}
\hline & $(1)$ & $(2)$ & $(3)$ & $(4)$ & $(5)$ & $(6)$ \\
& 1970 & 1980 & 1990 & 2000 & 2010 & 2018 \\
\hline \multicolumn{7}{c}{ Panel A: Men } \\
Top 1\% & 0.81 & 0.84 & 0.86 & 0.82 & 0.84 & 0.83 \\
Top 5\% & 0.83 & 0.80 & 0.80 & 0.88 & 0.82 & 0.80 \\
Top 10\% & 0.81 & 0.79 & 0.80 & 0.86 & 0.82 & 0.79 \\
Top 5-1\% & 0.71 & 0.68 & 0.66 & 0.71 & 0.64 & 0.63 \\
Top 10-1\% & 0.75 & 0.73 & 0.71 & 0.74 & 0.72 & 0.69 \\
Middle 40\% & 0.77 & 0.80 & 0.80 & 0.78 & 0.77 & 0.75 \\
Bottom 50\% & 0.76 & 0.76 & 0.75 & 0.74 & 0.74 & 0.75 \\
\hline & \multicolumn{7}{c}{ Panel B: Women } \\
Top 1\% & 0.24 & 0.29 & 0.30 & 0.35 & 0.40 & 0.59 \\
Top 5\% & 0.31 & 0.31 & 0.41 & 0.42 & 0.49 & 0.60 \\
Top 10\% & 0.41 & 0.40 & 0.51 & 0.51 & 0.53 & 0.63 \\
Top 5-1\% & 0.13 & 0.15 & 0.24 & 0.20 & 0.27 & 0.34 \\
Top 10-1\% & 0.29 & 0.29 & 0.39 & 0.36 & 0.40 & 0.48 \\
Middle 40\% & 0.59 & 0.53 & 0.58 & 0.59 & 0.60 & 0.63 \\
Bottom 50\% & 0.65 & 0.53 & 0.56 & 0.62 & 0.66 & 0.70 \\
\hline \hline
\end{tabular}

Notes: $\alpha_{i g}$ measures the income association between the gender distribution and the joint distribution for 51-65 age group. For detail see Equation 5. Top 1\%, 5\%, and 10\% report income shares held by those income groups in each income distribution. Top 5-1\% (10-1\%) is the income group that represents income of the top 5 (top 10) percent income earners excluding the income of the very top percentile. Source: Authors' calculation using IPUMS-CPS (https://cps.ipums.org/cps/). 
Table A.4: Top Decile Earners Married to various Deciles of the opposite Marginal Distribution, by age groups

\begin{tabular}{|c|c|c|c|c|c|c|c|c|c|c|}
\hline & $\begin{array}{c}(1) \\
\text { p1p10 }\end{array}$ & $\begin{array}{c}(2) \\
\text { p11p20 }\end{array}$ & $\begin{array}{c}(3) \\
\text { p21p30 }\end{array}$ & $\begin{array}{c}(4) \\
\text { p31p40 }\end{array}$ & $\begin{array}{c}(5) \\
\mathrm{p} 41 \mathrm{p} 50\end{array}$ & $\begin{array}{c}(6) \\
\mathrm{p} 51 \mathrm{p} 60\end{array}$ & $\begin{array}{c}(7) \\
\mathrm{p} 61 \mathrm{p} 70\end{array}$ & $\begin{array}{c}(8) \\
\text { p71p } 80\end{array}$ & $\begin{array}{c}(9) \\
\text { p81p90 }\end{array}$ & $\begin{array}{c}(10) \\
\text { p91p100 }\end{array}$ \\
\hline \multicolumn{11}{|c|}{ Panel A: 20-35 age group } \\
\hline \multicolumn{11}{|c|}{ Men's Top Decile } \\
\hline 1970 & 14.7 & 16.0 & 13.4 & 15.3 & 11.3 & 6.4 & 5.0 & 4.3 & 4.6 & 9.0 \\
\hline 1980 & 16.1 & 14.8 & 13.3 & 10.7 & 7.5 & 7.1 & 5.7 & 5.1 & 5.8 & 14.0 \\
\hline 1990 & 16.2 & 14.5 & 11.6 & 6.5 & 6.1 & 5.8 & 5.5 & 4.5 & 10.0 & 19.3 \\
\hline 2000 & 14.2 & 15.9 & 10.7 & 6.7 & 5.0 & 4.8 & 5.9 & 7.7 & 9.9 & 19.2 \\
\hline 2010 & 11.5 & 12.3 & 10.1 & 6.5 & 7.3 & 4.3 & 5.8 & 7.1 & 11.1 & 24.0 \\
\hline 2018 & 12.6 & 11.2 & 8.2 & 6.7 & 3.6 & 5.3 & 5.6 & 7.0 & 12.0 & 28.0 \\
\hline \multicolumn{11}{|c|}{ Women's Top Decile } \\
\hline 1970 & 13.2 & 7.5 & 8.7 & 10.8 & 9.7 & 9.8 & 11.6 & 12.3 & 7.6 & 8.7 \\
\hline 1980 & 8.2 & 5.7 & 5.9 & 7.1 & 11.2 & 12.4 & 12.4 & 10.4 & 12.9 & 13.8 \\
\hline 1990 & 6.2 & 5.2 & 5.5 & 6.6 & 7.0 & 9.6 & 11.6 & 14.3 & 15.5 & 18.6 \\
\hline 2000 & 6.9 & 4.7 & 4.6 & 6.1 & 7.7 & 7.9 & 12.0 & 16.2 & 15.0 & 18.9 \\
\hline 2010 & 3.1 & 2.0 & 1.9 & 3.1 & 4.1 & 4.2 & 4.8 & 7.1 & 9.2 & 60.5 \\
\hline 2018 & 2.7 & 1.1 & 1.9 & 2.2 & 2.7 & 3.8 & 5.9 & 7.8 & 9.6 & 62.2 \\
\hline
\end{tabular}

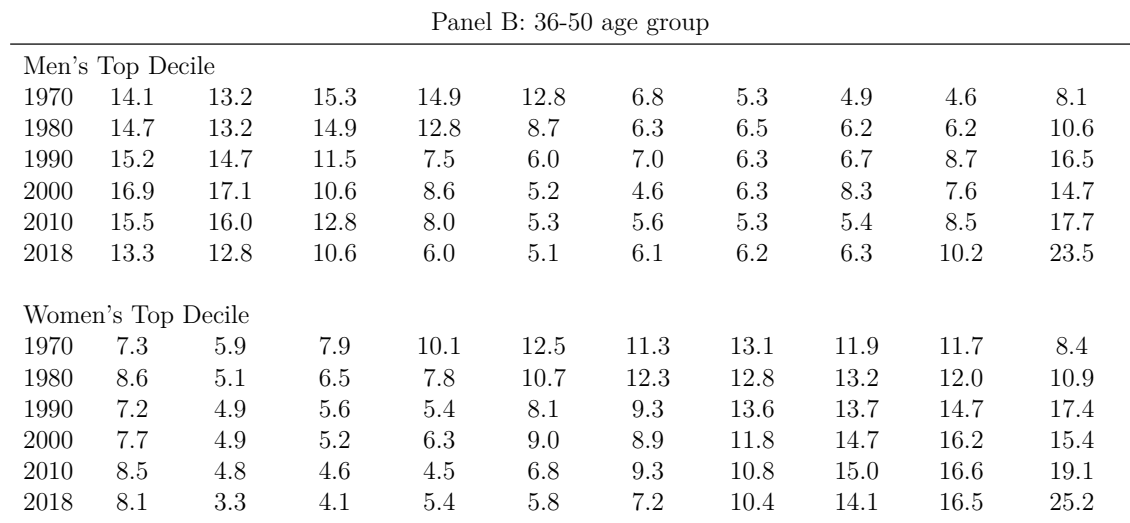

\begin{tabular}{|c|c|c|c|c|c|c|c|c|c|c|}
\hline \multicolumn{11}{|c|}{ Panel C: 51-65 age group } \\
\hline \multicolumn{11}{|c|}{ Men's Top Decile } \\
\hline 1970 & 14.2 & 12.3 & 11.0 & 11.0 & 10.8 & 8.7 & 7.2 & 5.7 & 5.2 & 13.8 \\
\hline 1980 & 12.7 & 11.8 & 11.4 & 11.8 & 11.0 & 10.4 & 7.1 & 6.2 & 6.7 & 11.0 \\
\hline 1990 & 10.6 & 8.8 & 9.3 & 9.3 & 8.6 & 9.3 & 7.0 & 7.8 & 9.4 & 19.8 \\
\hline 2000 & 9.8 & 8.9 & 10.8 & 10.7 & 8.4 & 6.3 & 8.5 & 7.0 & 10.8 & 18.9 \\
\hline 2010 & 11.2 & 11.2 & 11.2 & 11.1 & 7.4 & 5.3 & 7.7 & 7.0 & 9.1 & 18.8 \\
\hline 2018 & 10.2 & 10.2 & 10.6 & 10.2 & 5.6 & 6.7 & 7.1 & 7.8 & 11.7 & 19.7 \\
\hline \multicolumn{11}{|c|}{ Women's Top Decile } \\
\hline 1970 & 7.5 & 6.3 & 5.9 & 7.7 & 9.7 & 13.1 & 11.1 & 12.8 & 12.6 & 13.4 \\
\hline 1980 & 7.5 & 8.1 & 7.9 & 8.5 & 9.4 & 12.3 & 11.3 & 11.3 & 13.4 & 10.2 \\
\hline 1990 & 6.4 & 6.1 & 8.2 & 5.4 & 6.6 & 9.3 & 11.6 & 13.6 & 15.3 & 17.5 \\
\hline 2000 & 6.1 & 6.2 & 4.5 & 7.3 & 7.2 & 8.9 & 10.9 & 14.1 & 16.8 & 18.1 \\
\hline 2010 & 8.5 & 8.1 & 4.8 & 4.8 & 5.9 & 9.6 & 10.2 & 13.7 & 16.0 & 18.5 \\
\hline 2018 & 7.3 & 7.3 & 5.9 & 5.8 & 5.6 & 7.1 & 9.2 & 14.0 & 18.3 & 19.5 \\
\hline
\end{tabular}

Notes: This table lists, by age group, the share of the men and women from the top earning decile of the gender distributions married to various income deciles in the opposite gender distribution. The income deciles are ranked form the lowest, p1p10, to the highest, p90p100. Reading: In 1970, 14.7 percent (column 1, row: Men's Top Decile in 1970) of the top decile of men from the men's labor income distribution were married to the women in the bottom decile of the women's labor income distribution. The share married to the top decile of women in the same year was 9.0 percent (column 10, row: Men's Top Decile in 1970). The shares in each year sum to 100 percent. Source: Authors' calculation using IPUMS-CPS (https://cps.ipums.org/cps/). 
Figure A.1: Income Distribution of the Marginal Distributions in 1970 and 2018

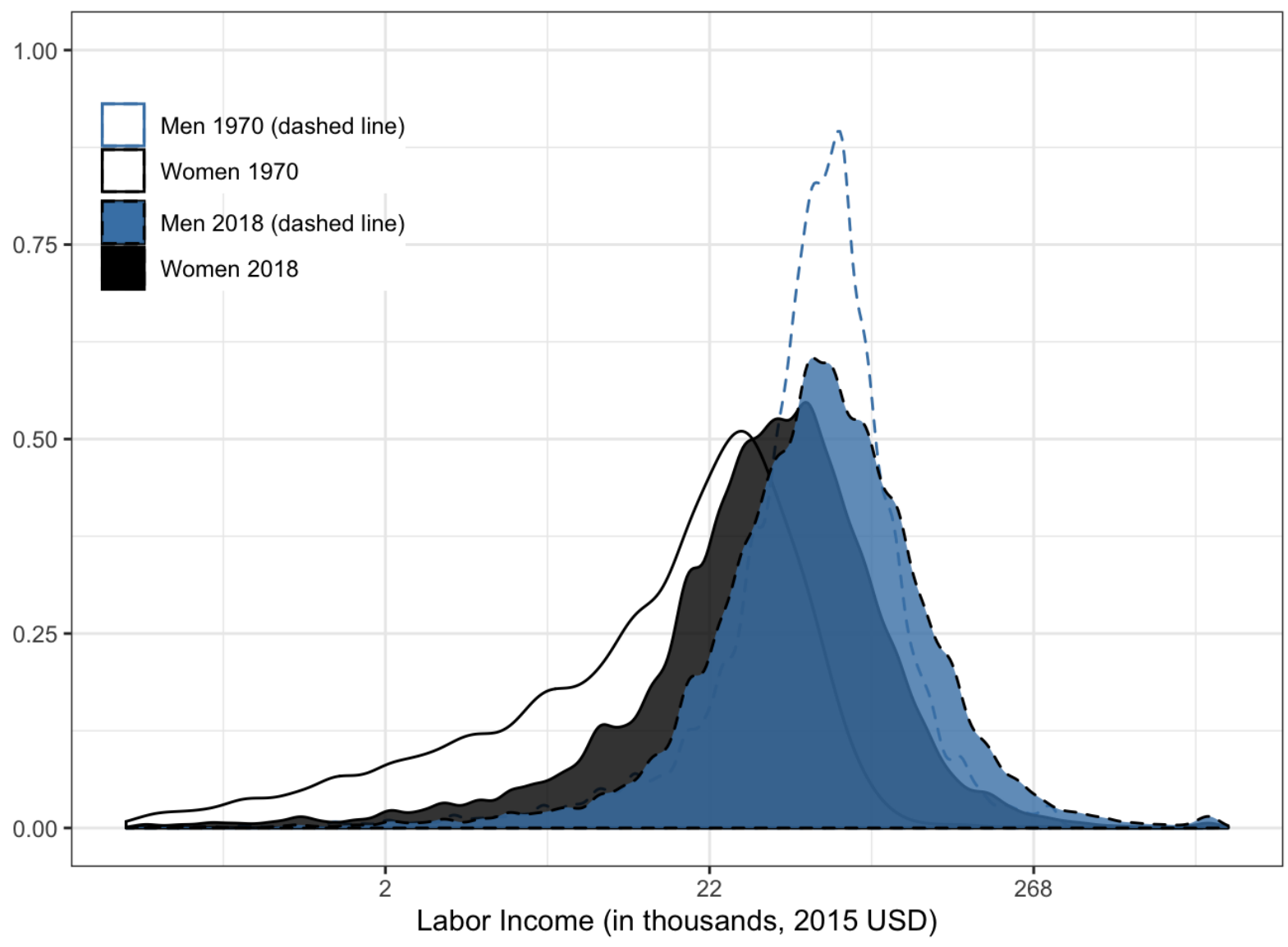

Notes: This figures shows the labor income distribution of the men's and women's distribution in 1970 and in 2018. Labor income is reported in 2015 USD. Source: Author's calculation using IPUMS-CPS. 


\section{Figure A.2: Perfectly Co- and Counter-monotonic Copula Distributions}

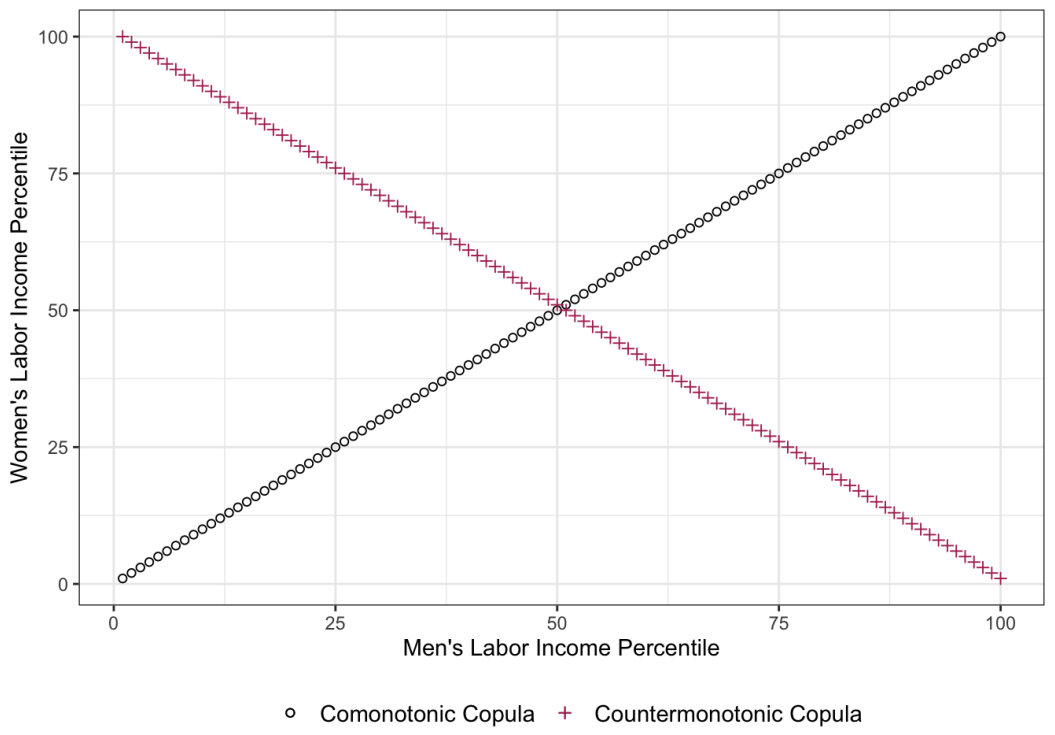

Notes: This figures shows the rank-rank correlation between the gender distributions for a perfectly comonotonic and a perfectly countermonotonic copula distribution. Each axis is ranked according to the gender's labor income from the poorest percentile (left or bottom) to the richest percentile (right or top).

Figure A.3: Random Distribution

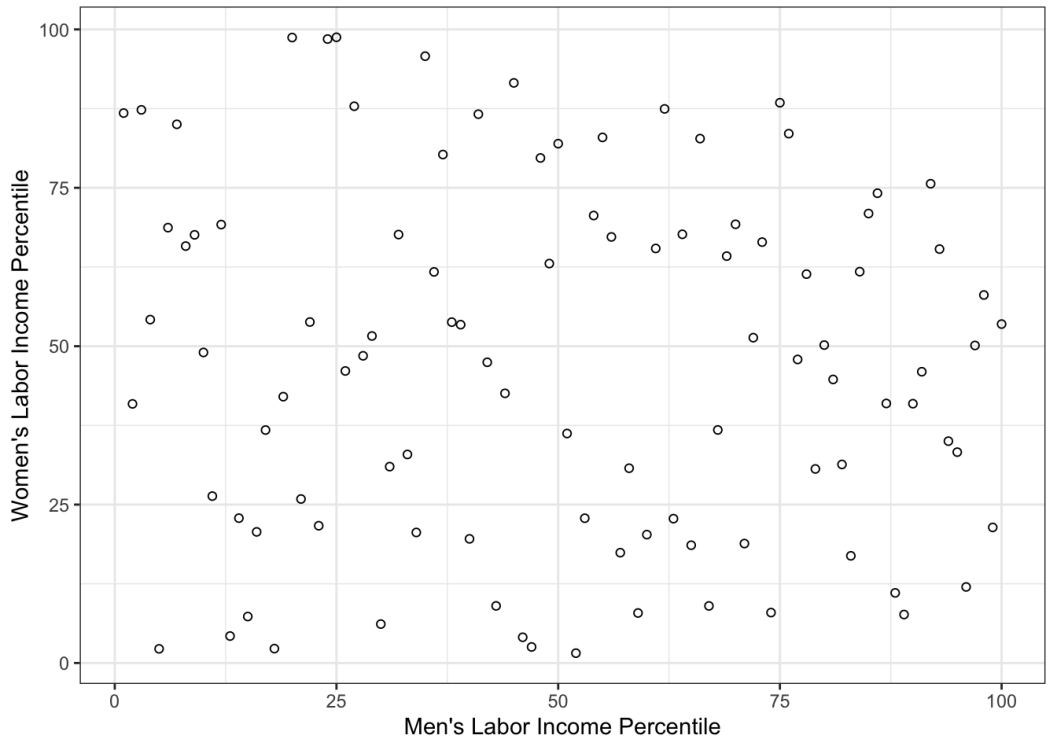

Notes: This figures shows a random rank-rank correlation between the gender distributions. Each axis is ranked according to the gender's labor income from the poorest percentile (left or bottom) to the richest percentile (right or top). 
Figure A.4: Share of men from the men's top decile married to women from the top and bottom women's deciles, 20-35 age group

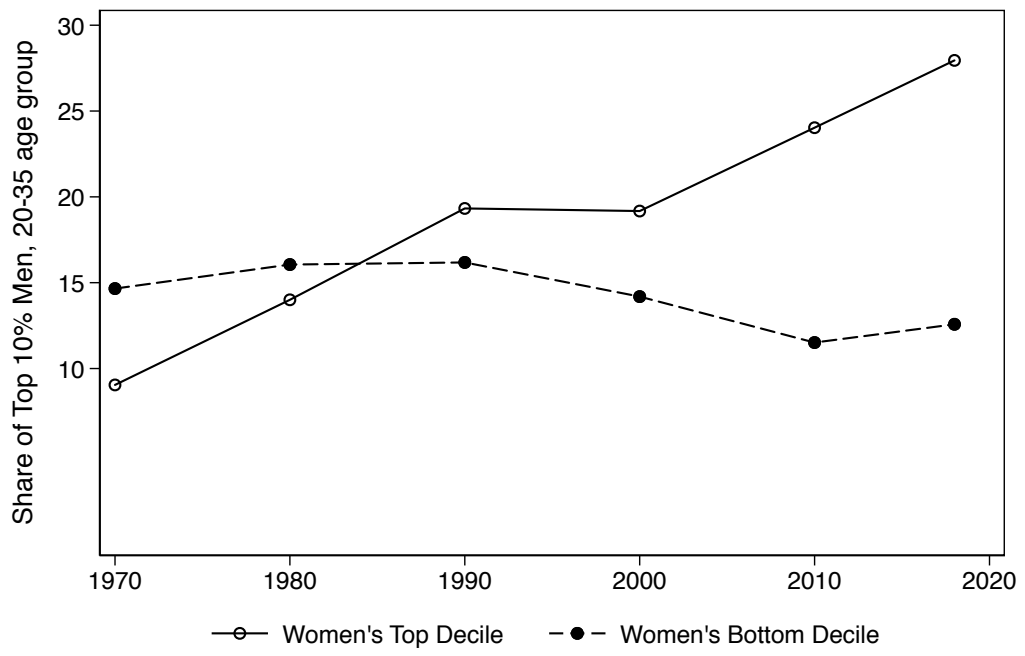

Notes: This figure shows the share (in percent) of men in the 20-35 age group from the men's top labor income decile married to women from the top (solid line) and bottom (broken line) women's labor income deciles for the period 1970-2018. Source: Columns (1) and (10), Panel B in Table 5.

Figure A.5: Share of women from the women's top decile married to men from the top and bottom men's deciles, 20-35 age group

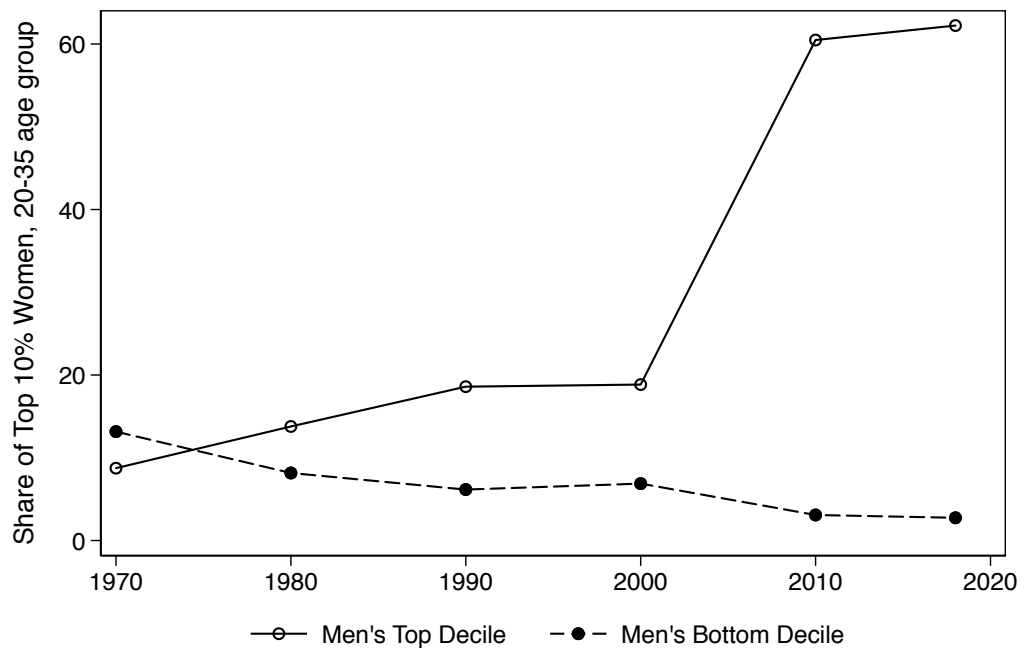

Notes: This figure shows the share (in percent) of women in the 20-35 age group from the women's top labor income decile married to men from the top (solid line) and bottom (broken line) men's labor income deciles for the period 1970-2018. Source: Columns (1) and (10), Panel B in Table 5. 
Figure A.6: Share of men from the men's top decile married to women from the top and bottom women's deciles, 36-50 age group

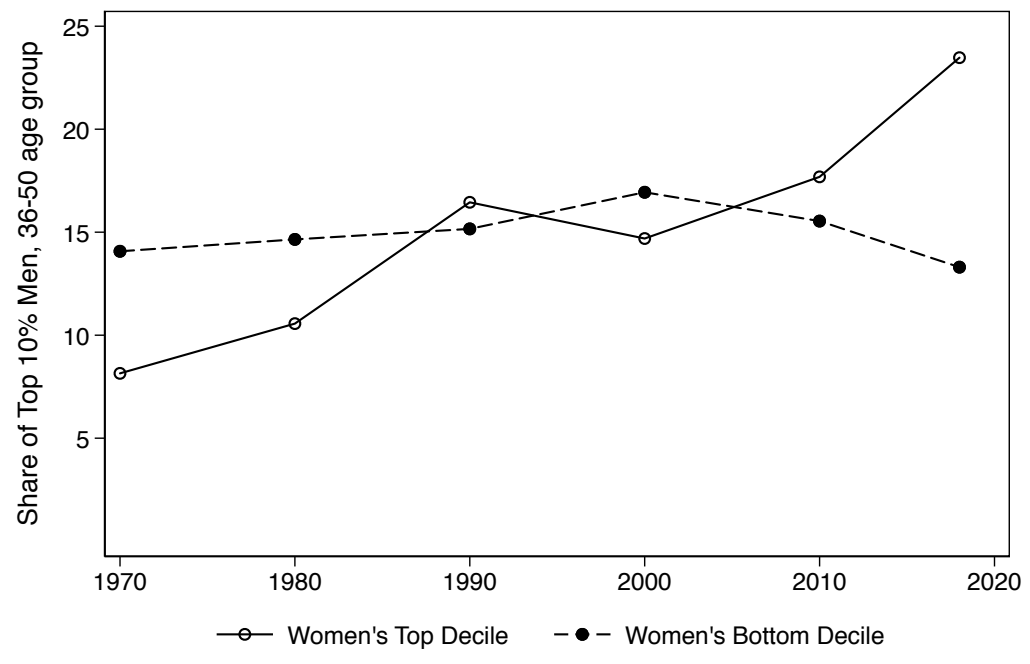

Notes: This figure shows the share (in percent) of men in the 36-50 age group from the men's top labor income decile married to women from the top (solid line) and bottom (broken line) women's labor income deciles for the period 1970-2018. Source: Columns (1) and (10), Panel B in Table 5.

Figure A.7: Share of women from the women's top decile married to men from the top and bottom men's deciles, 36-50 age group

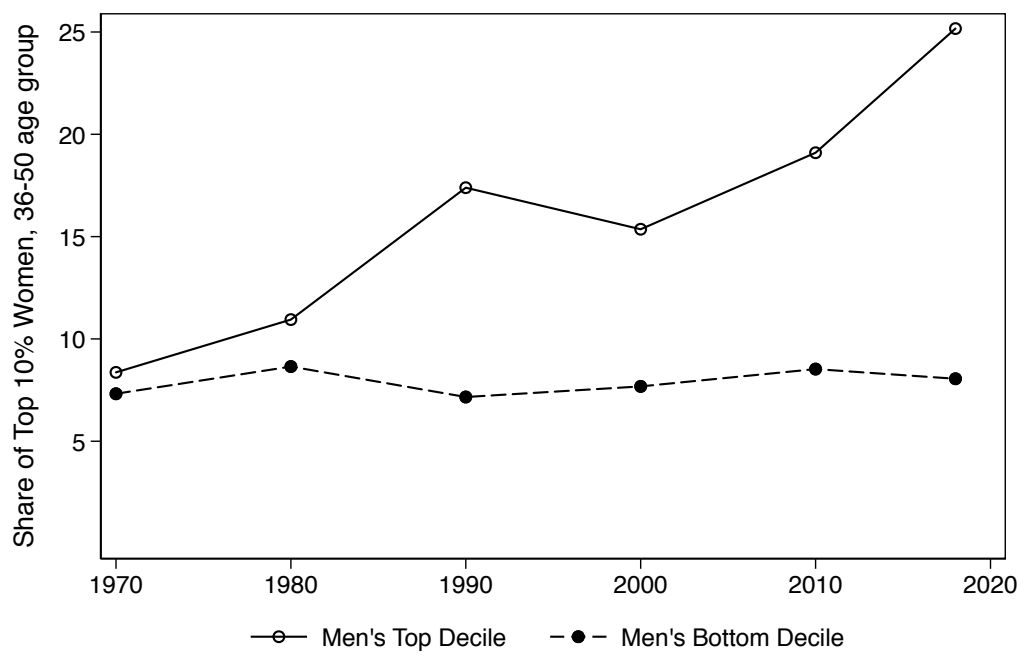

Notes: This figure shows the share (in percent) of women in the 36-50 age group from the women's top labor income decile married to men from the top (solid line) and bottom (broken line) men's labor income deciles for the period 1970-2018. Source: Columns (1) and (10), Panel B in Table 5. 
Figure A.8: Share of men from the men's top decile married to women from the top and bottom women's deciles, 51-65 age group

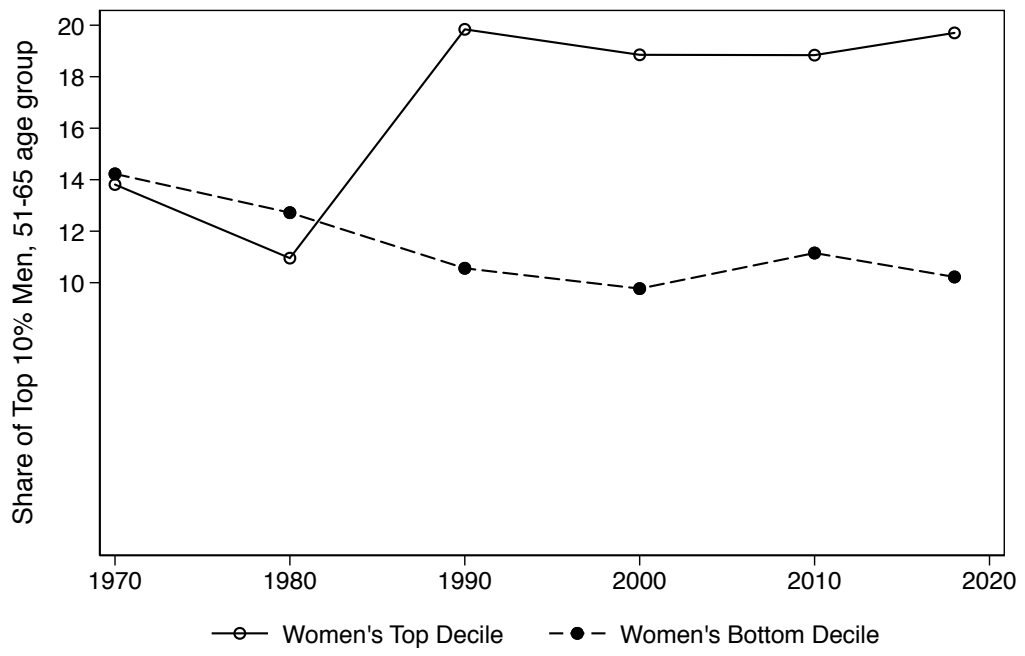

Notes: This figure shows the share (in percent) of men in the 51-65 age group from the men's top labor income decile married to women from the top (solid line) and bottom (broken line) women's labor income deciles for the period 1970-2018. Source: Columns (1) and (10), Panel B in Table 5.

Figure A.9: Share of women from the women's top decile married to men from the top and bottom men's deciles, 51-65 age group

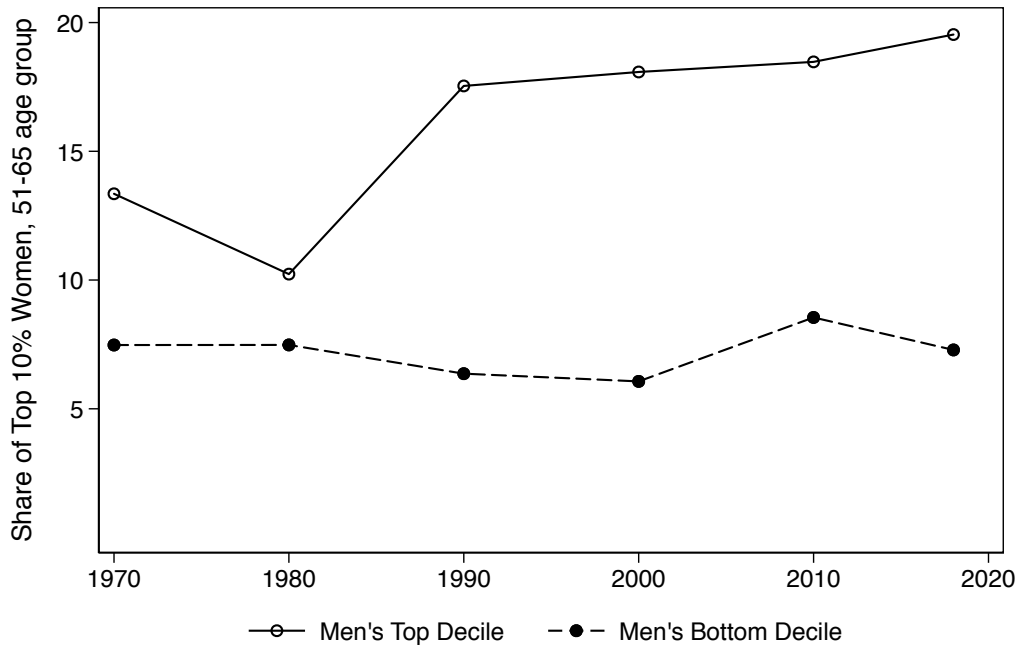

Notes: This figure shows the share (in percent) of women in the 51-65 age group from the women's top labor income decile married to men from the top (solid line) and bottom (broken line) men's labor income deciles for the period 1970-2018. Source: Columns (1) and (10), Panel B in Table 5. 
Figure A.10: Rank-rank correlation for each percentile in 1970 and 2018, using median

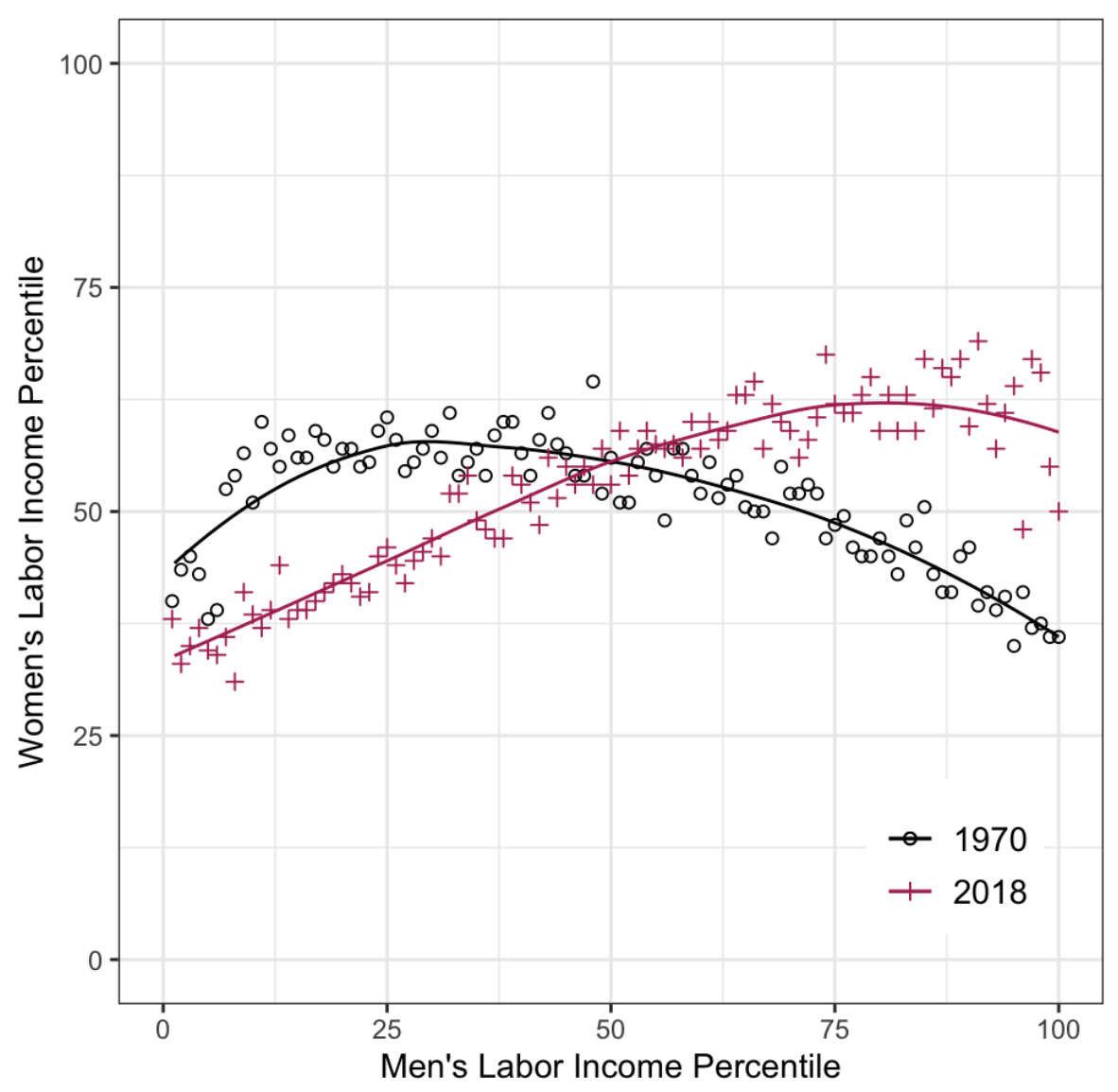

Notes: This figure shows the rank-rank correlation between each percentile of the marginal distributions in 1970 and 2018. For each percentile of the men's distribution, it shows the median rank of their partner in the women's distribution. The percentiles are ranked by each gender's labor income from the poorest percentile (left) to the richest percentile (right). A non-parametric regression line is fitted for each year. Source: Authors' calculation using IPUMS-CPS (https://cps.ipums.org/cps/). 
Figure A.11: Income Share of Top 10\% Relative to the Bounds
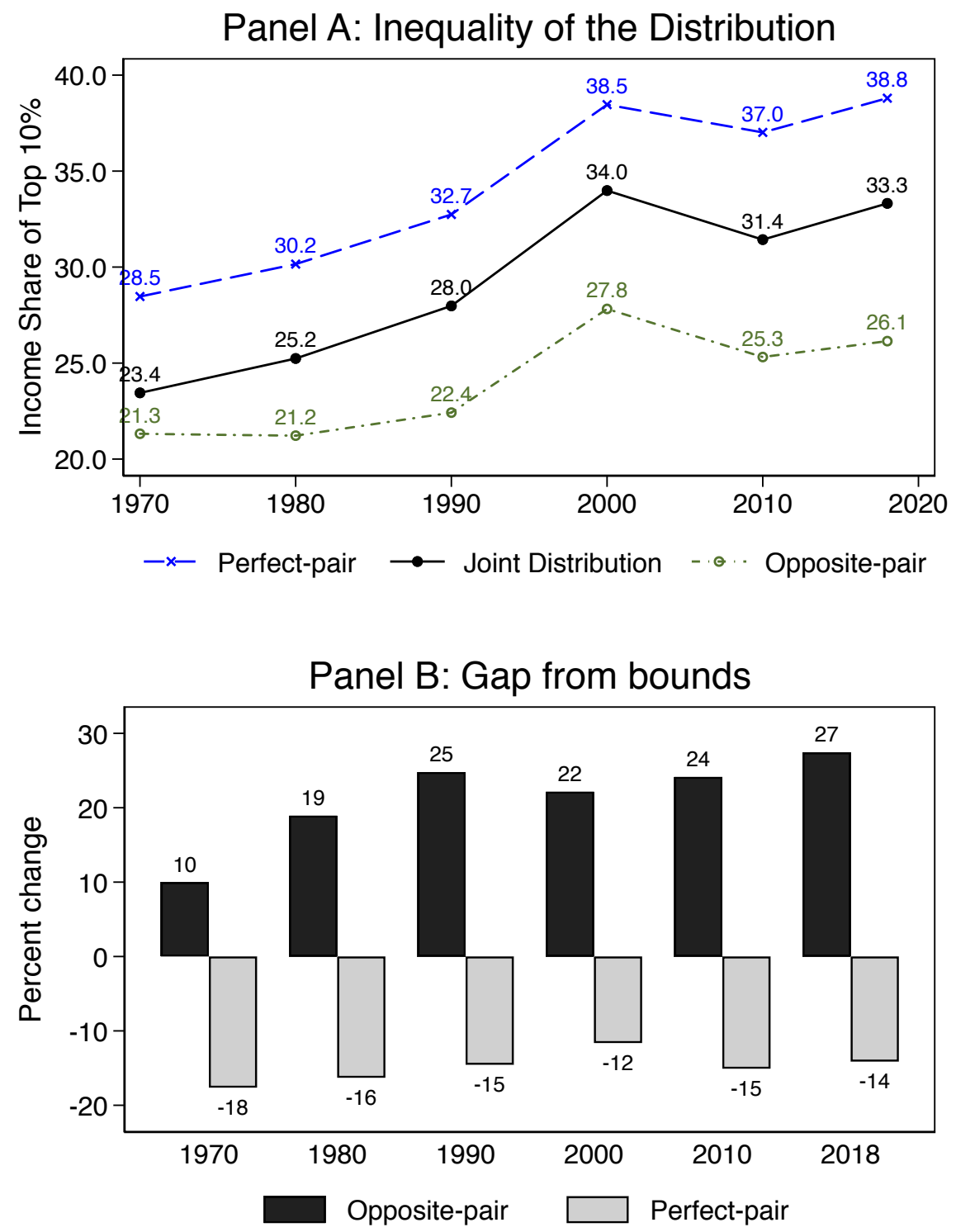

Notes: Panel A of this figure shows the trends in the income share of the top decile of earners in the current joint distribution and the perfect-pair (upper-bound for inequality) and opposite-paired (lower-bound for inequality) distributions. Panel B shows the trend in the percent increase (decrease) in the share of income of the top decile of the current joint distribution from the lower (upper) bound. Source: Authors' calculation using IPUMS-CPS (https://cps.ipums.org/cps/). 